\title{
The Rainfall Sensitivity of Tropical Net Primary Production in CMIP5 Twentieth- and Twenty-First-Century Simulations*
}

\author{
Robinson I. Negrón-Juárez, William J. Riley, Charles D. Koven, And Ryan G. Knox \\ Earth Sciences Division, Lawrence Berkeley National Laboratory, Berkeley, California \\ PHILIP G. TAYLOR \\ Department of Ecology and Evolutionary Biology, University of Colorado Boulder, Boulder, Colorado \\ JEFFREY Q. CHAMBERS \\ Earth Sciences Division, Lawrence Berkeley National Laboratory, and Department of Geography, \\ University of California, Berkeley, Berkeley, California
}

(Manuscript received 8 October 2014, in final form 20 August 2015)

\begin{abstract}
In this study, the authors used the relationship between mean annual rainfall (MAR) and net primary production (NPP) (MAR-NPP) observed in tropical forests to evaluate the performance (twentieth century) and predictions (twenty-first century) of tropical NPP from 10 earth system models (ESMs) from phase 5 of the Coupled Model Intercomparison Project (CMIP5). Over the tropical forest domain most of the CMIP5 models showed a positive correlation between NPP and MAR similar to observations. The GFDL, CESM1, CCSM4, and Beijing Normal University (BNU) models better represented the observed MAR-NPP relationship. Compared with observations, the models were able to reproduce the seasonality of rainfall over areas with long dry seasons, but NPP seasonality was difficult to evaluate given the limited observations. From 2006 to 2100, for representative concentration pathway 8.5 (RCP8.5) (and most RCP4.5 simulations) all models projected increases in NPP, but these increases occurred at different rates. By the end of the twenty-first century the models with better performance against observed NPP-MAR projected increases in NPP between $\sim 2 \%$ (RCP4.5) and 19\% (RCP8.5) relative to contemporary observations, representing increases of $\sim 9 \%$ and $\sim 25 \%$ relative to their historical simulations. When climate and $\mathrm{CO}_{2}$ fertilization are considered as separate controls on plant physiology, the current climate yields maximum productivity. However, as future climate changes become detrimental to productivity, $\mathrm{CO}_{2}$ fertilization becomes the dominant response, resulting in an overall increase in NPP toward the end of the twentyfirst century. Thus, the way in which models represent $\mathrm{CO}_{2}$ fertilization affects their performance. Further studies addressing the individual and simultaneous effect of other climate variables on NPP are needed.
\end{abstract}

\section{Introduction}

Net primary production (NPP) is the difference between $\mathrm{CO}_{2}$ fixed by vegetation through photosynthesis [or gross primary production (GPP)] and the loss of carbon due to autotrophic respiration. Thus, NPP represents the net rate

\footnotetext{
* Supplemental information related to this paper is available at the Journals Online website: http://dx.doi.org/10.1175/JCLI-D-14-00675.s1.

Corresponding author address: Robinson I. Negrón-Juárez, Earth Sciences Division, Lawrence Berkeley National Laboratory, 1 Cyclotron Rd., Berkeley, CA 94720.

E-mail: robinson.inj@lbl.gov
}

of carbon gain by vegetation (Clark et al. 2001a) and therefore represents the potential of vegetation to sequester anthropogenic $\mathrm{CO}_{2}$ emissions.

NPP tends to be highest in warm moist environments and lowest in cold dry environments (Chapin et al. 2003). Among Earth's biomes, tropical forests generally have the highest annual NPP as a result of favorable climate and efficient nutrient recycling (Cleveland et al. 2013; Malhi et al. 2004; Quesada et al. 2012). Rainfall and temperature play a large role in controlling both long-(Del Grosso et al.

\footnotetext{
Publisher's Note: This article was revised on 14 December 2015 to correct the online version of Table 1, which was mistakenly replaced when originally published.
} 
2008; Schuur 2003) and short-term rates (Doughty et al. 2014; Gatti et al. 2014) of tropical NPP. Recent evidence of drought-induced dieback of the Amazon suggests that low rainfall combined with high temperature anomalies can dramatically reduce tropical $\mathrm{CO}_{2}$ uptake (Malhi et al. 2009), though the mechanisms remain uncertain.

The potential negative effects of increasing temperature and shifts in rainfall on forest NPP could be offset by $\mathrm{CO}_{2}$ fertilization (Norby et al. 2005), although the effect in tropical forests may start to saturate at a $\mathrm{CO}_{2}$ concentration of $\sim 600 \mathrm{ppm}$ (Ainsworth and Long 2005). Some studies suggest that tropical rain forests may already be growing faster as a result of $\mathrm{CO}_{2}$ enrichment (Lewis et al. 2009), a response that is mechanistically represented in the earth system models (ESMs) (Arora et al. 2013). However, other lines of observational evidence suggest that the $\mathrm{CO}_{2}$ fertilization response is overestimated (Chambers and Silver 2004; Clark et al. 2013; Semboli et al. 2014; Silva and Anand 2013; Wright 2013).

Atmospheric $\mathrm{CO}_{2}$ concentrations have risen from $\sim 280$ to $\sim 400 \mathrm{ppm}$ over the past $150 \mathrm{yr}$ (NOAA 2014) and are projected to reach $500-1000 \mathrm{ppm}$ by 2100 , leading to a global temperature increase of $2^{\circ}-4^{\circ} \mathrm{C}$ and changes in rainfall distribution and intensity (Allison 2009; IPCC 2013; Lacis et al. 2010). The response of NPP to these factors can be explored with ESMs, which attempt to simulate the relevant physical, chemical, and biological components of the earth system now and in the future (Arora et al. 2013). Nevertheless, field studies are crucial for calibrating and benchmarking ESMs.

The latest versions of state-of-the-art ESMs are part of phase 5 of the Coupled Model Intercomparison Project (CMIP5) (Taylor et al. 2012) and offer a unique opportunity to study components of the terrestrial carbon cycle and their responses to current and future climate (Arora et al. 2013; Friedlingstein et al. 2014; Hou et al. 2013; Li et al. 2015; Shao et al. 2013). For instance, early results from observational and modeling experiments agree that the combination of warming and increased precipitation generally has a positive effect on NPP and ecosystem respiration, while the combination of warming and reduced precipitation has a negative effect on NPP (Luo et al. 2008; Wu et al. 2011).

The purpose of this study is therefore to evaluate the ability of the CMIP5 models to represent the observed relationship between NPP and rainfall in tropical forests. Our study aims to expand on previous analyses by 1) including observations from lowland tropical sites, 2) comparing the observed relationships between MAR and NPP with similar relationships predicted by CMIP5 ESMs, 3) developing a metric that can be used to benchmark ESMs land model predictions of NPP sensitivity to rainfall, and 4) using this metric to infer the models' ability to predict NPP over the twenty-first century.

\section{Data and methods}

\section{a. Study area}

This study focuses on tropical forests $\left(23.43^{\circ} \mathrm{S}-23.43^{\circ} \mathrm{N}\right.$ over all longitudes) (Fig. 1a). Tropical forest areas were selected using the Moderate Resolution Imaging Spectroradiometer (MODIS) land-cover type climate modeling grid (CMG) product (MCD12C1 version 051; available at https://lpdaac.usgs.gov/) (Friedl et al. 2010) for the year 2005. MCD12C1 is available at $0.05^{\circ}$ resolution and includes cover type assessment, percent distribution, and quality control information. The International Geosphere-Biosphere Programme (IGBP) global vegetation classification (Loveland and Belward 1997) of evergreen broadleaf forests was used to identify tropical forests. A conservative mask of tropical forested areas was created by considering only pixels with good quality (flag 0 in quality control files), forest land cover greater than $80 \%$, and reliability (assessment) greater than $85 \%$ (Fig. S1 in the supplementary material). This forest mask was applied to all model simulations analyzed here.

\section{b. CMIP5 models and experiments}

ESMs couple the atmosphere, ocean, and land surface. Ten ESMs from the CMIP5 (available at http:// cmip-pcmdi.llnl.gov/cmip5/) were used in this study (Table 1): Beijing Normal University-ESM (BNU); the Second Generation Canadian ESM (CanESM2); the Community Climate System version 4 (CCSM4), which is a subset of the Community Earth System Model version 1 (CESM1); the Geophysical Fluid Dynamics Laboratory ESM (GFDL); the Goddard Institute for Space Studies general circulation model (GISS); the Hadley Centre Global Environment Model version 2 (HadGEM2); L'Institut Pierre-Simon Laplace ESM (IPSL); the Model for Interdisciplinary Research on Climate ESM (MIROC); and the Max Planck Institute ESM (MPI).

A brief description of the CMIP5 models is presented, and complete details can be found in the references listed in Table 1. The land surface model in BNU is BNUCOLM3, which has an interactive carbon cycle model [BNUDGVM $(\mathrm{C} / \mathrm{N})]$. The CanESM2 (Arora et al. 2011) uses the Canadian Terrestrial Ecosystem Model (CTEM). In the CESM1 (Hurrell et al. 2013) the atmospheric component uses the Community Atmosphere Model, version 5 (CAM5) and the Whole Atmosphere Community Climate Model (WACCM), with biogeochemistry (BGC) and chemistry (FASTCHEM) (Hurrell et al. 2013). In CESM1 and CCSM4 (Gent et al. 2011) the land surface model is the Community Land Model, version 4 (CLM4.0) (Oleson et al. 2010). The GFDL (Delworth et al. 2006; Dunne et al. 2012, 2013) includes ESM2M and ESM2G, which differ only in the physical ocean component. 
a

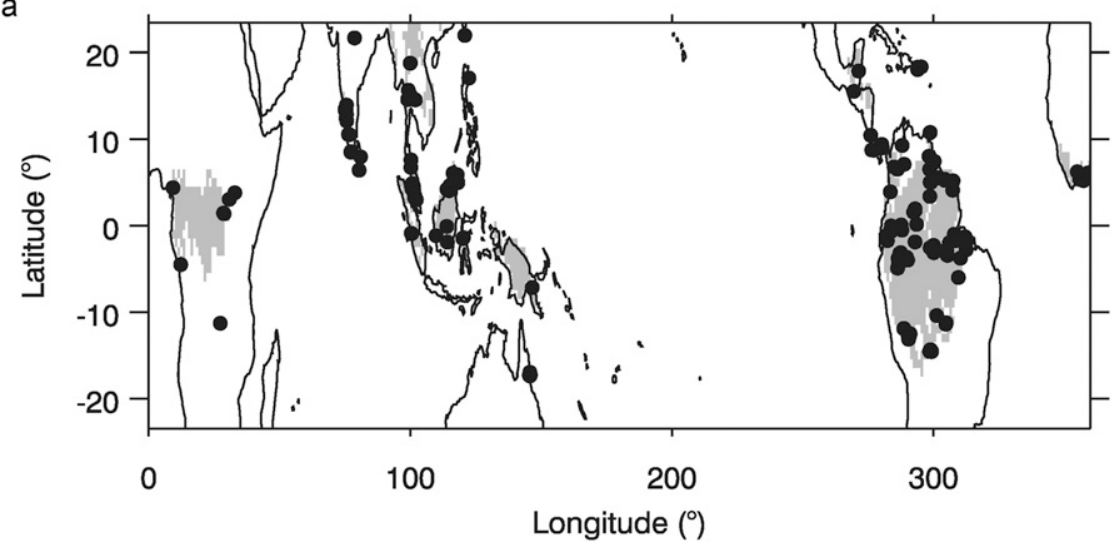

b

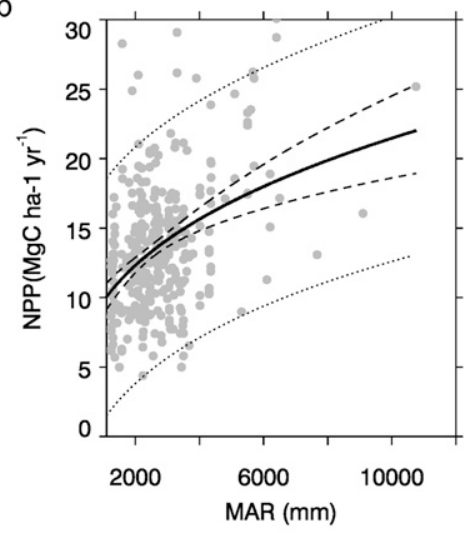

FIG. 1. (a) A map of the location of tropical rain forests (gray color) in 2005 (from MODIS MCD12C1) and the location of the 327 sites used in this study (black dots, not all distinctly visible). (b) The relationship between NPP and MAR from all 327 sites. The solid line is the fitted curve (MAR-NPP ${ }_{\text {obs }}$ ), NPP $=a \times \mathrm{MAR}^{b}, a=0.91 \pm 0.3$ ( \pm standard error), $b=0.34 \pm 0.04, p<0.0001$, and RMSEA $=0.04$. The dashed lines represent the $95 \%$ confidence bands, and the dotted lines represent the $95 \%$ prediction bands.

ESM2M uses a depth-based vertical coordinate [Modular Ocean Model, version 4.1 (MOM4.1)] and ESM2G uses a sigma coordinate mixed layer and density-based vertical coordinate in the interior [Generalized Ocean Layer Dynamics (GOLD)] (Dunne et al. 2012). GFDL uses a new integrated land model, LM3 (Milly et al. 2014). GISS (Schmidt et al. 2014) includes versions corresponding to CMIP3 and AR4 (GISS-ER and GISS-EH2) as well as CMIP5 and AR5 (GISS-ES-R and GISS-E2-H), where R and $\mathrm{H}$ denote different ocean models, and for clarity the notation E2-R/H and E-R/H2 was used. HadGEM2-ES includes all the Earth system components, and HadGEM2$\mathrm{CC}$ includes all the earth system components except gasphase tropospheric chemistry (Collins et al. 2011; Martin et al. 2011). HadGEM2 models include the TRIFFID dynamic vegetation scheme (Collins et al. 2011). IPSL-CM5A is an improved extension of IPSL-CM4, and IPSL-CM5B includes a new set of physical parameterizations in the atmospheric model (Dufresne et al. 2013). In MIROC the land surface model is Minimal Advanced Treatments of Surface Interaction and Runoff (MATSIRO) (Watanabe et al. 2011) and MPI uses JSBACH (Giorgetta et al. 2013).

The CMIP5 simulations used in this study were both historical (1850-2005) and future projections (2006-2100). Historical simulations, also referred to as twentieth century, can be compared directly with observations (Taylor et al. 2012). The projection simulations used in this study are forced with representative concentration pathways (RCPs) from a business-as-usual scenario (RCP8.5; the radiative forcing increases through the twenty-first century before reaching a level of about $8.5 \mathrm{~W} \mathrm{~m}^{-2}$ ) and a midrange mitigation emissions scenario (RCP4.5) (van Vuuren et al. 2011). Historical and RCP simulations are coupled simulations since the increase of $\mathrm{CO}_{2}$ affects both the climate (radiatively active) and the carbon cycle (biogeochemically active) components of the models. To separate the effect of climate change and $\mathrm{CO}_{2}$ on NPP, we used the ESM feedback version 2 (esmFdbk2) and ESM fixed climate version 2 (esmClimFix2) simulations that encompass the period 1850-2100. These simulations are designed to determine the effects of carbon cycle feedbacks for the historical period and the RCP4.5 future scenario (Taylor et al. 2012). In the esmFdbk2 simulations the climate responds to the increase of atmospheric $\mathrm{CO}_{2}$ (the model is radiatively active; Burke et al. 2013), but the $\mathrm{CO}_{2}$ increase is hidden from the carbon cycle (the model is biogeochemically inert with respect to $\mathrm{CO}_{2}$ changes; Burke et al. 2013), which is forced with the preindustrial atmospheric $\mathrm{CO}_{2}$ value. Thus, esmFdbk2 simulations show the direct effect of climate change on NPP. Contrary to esmFdbk2, the esmFixClim2 simulations are radiatively inert but biogeochemically active and show the direct effect of $\mathrm{CO}_{2}$ on NPP. Therefore, esmFdbk2 and esmFixClim2 simulations isolate the system's response to changes in climate and $\mathrm{CO}_{2}$ concentrations, respectively (Arora et al. 2013). At the time of this study, esmFdbk 2 and esmClimFix2 simulations were available for the CanESM2, CESM1 (up to 2005), GFDL, GISS, HadGEM2, and IPSL models. All ensemble members available at the time of this study were used and were averaged per institution.

The CMIP5 monthly variables analyzed were net primary production (megagrams of carbon per hectare per year), precipitation (PR; millimeters per month), nearsurface air temperature (TAS; degrees Celsius), and surface downwelling shortwave radiation (RSDS; watts per meter squared). For purposes of comparison and to minimize bias associated with different resolutions all model variables were regridded to $2.5^{\circ}$. 


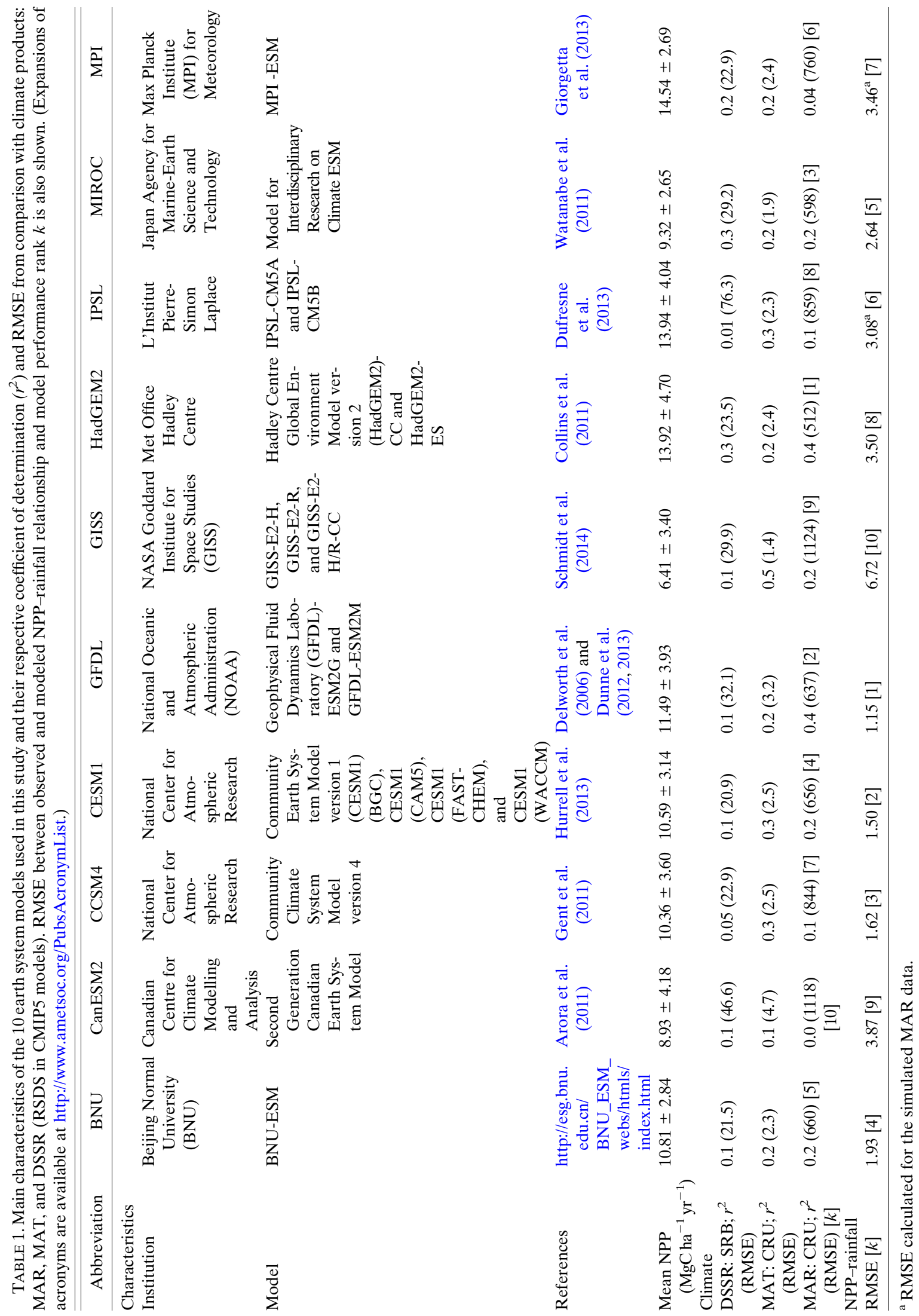




\section{c. NPP datasets}

This study used published data from old-growth lowland tropical forest sites with measurements of aboveground NPP (ANPP; stem growth and litterfall), mean annual temperature (MAT), mean annual rainfall (MAR), and elevation. The data were obtained from the literature or online databases (P. G. Taylor 2014, personal communication; references and sources of data for all sites used are listed in Table S1 of the supplementary material). These data have been presented in previous NPP synthesis (e.g., Aragão et al. 2009; Ciais et al. 2011; Cleveland et al. 2011; Girardin et al. 2010; Malhi et al. 2004, 2011) or dataset collections (e.g., ORNL Net Primary Production Project, available at http://daac.ornl.gov/NPP/npp_home.shtml). We considered data from only lowland forests since they represent the largest portion of tropical forests (Cleveland et al. 2011). A threshold of MAR $\geq 1100 \mathrm{~mm}$ (Fig. 1a; see also Fig. S2 in the supplementary material) was further considered to define lowland tropical forests. In total 327 site data were used in this study (Fig. 1a).

Site ANPP was used to calculate site NPP as follows: $\mathrm{NPP}=\mathrm{ANPP}+c \times \mathrm{ANPP}$, where $c$ is a factor between 0.2 and 1.2 (Clark et al. 2001b). A Monte Carlo simulation over a range of values of $c$ determined that $c=0.71 \pm 0.08$ produced significantly similar mean NPP value $[11.8 \pm$ $5.5 \mathrm{MgCha}^{-1} \mathrm{yr}^{-1}$ (mean \pm standard deviation) $t$ statistic; $95 \%$ confidence interval] and close to the mean value from direct observations $\left(11.86 \pm 2.47 \mathrm{MgCha}^{-1} \mathrm{yr}^{-1}\right)$ found in 71 tropical lowland forests sites with MAR > $1100 \mathrm{~mm}$ (Malhi et al. 2011). The higher standard deviation in site NPP may be related to the larger number of sites that we used. For simplicity, we used $c=0.71$ in our calculations, but the effects of $c=0.71 \pm 0.08$ in our results were properly discussed. The temporal variability of NPP was not addressed in this study owing to the lack of time series of observed NPP and the fact that NPP products derived from satellites (Zhao and Running 2010) have not been thoroughly validated in tropical forests (Malhi et al. 2015; Medlyn 2011; Samanta et al. 2011).

\section{d. Climate datasets}

A set of rainfall, temperature, and surface radiation datasets were used for comparison with CMIP5 models output. Monthly rainfall and temperature data from the Climatic Research Unit (CRU) at $0.5^{\circ}$ global resolution (CRU TS3.21) (Harris et al. 2013) were used in this study. These datasets (available at http://www.cru.uea.ac.uk/cru/ data/hrg/) are hereafter referred to as the CRU rainfall and CRU temperature datasets. A second rainfall dataset from the Global Precipitation Climatology Centre (GPCC) at $0.5^{\circ}$ resolution (Schneider et al. 2014) was also used. Downwelling shortwave surface solar radiation was retrieved from the European Centre for Medium-Range Weather Forecasts (ECMWF) 40-yr Re-Analysis (ERA40; $0.5^{\circ}$ resolution; available at http://data-portal.ecmwf.int/) $(0.2-4 \mu \mathrm{m})$ and the Global Energy and Water Cycle Experiment (GEWEX) Surface Radiation Budget (SRB; $1^{\circ}$ resolution; available at http://gewex-srb.larc.nasa.gov/). ECMWF reanalysis data for the period 1957-2002 and SRB data from 1983 to 2007 were compared with observations. The SRB product showed higher correlation with the observational data (Fig. S3 in the supplementary material) and was therefore chosen as the radiation data for use in this study. These climate datasets were all regridded to $2.5^{\circ}$ for comparison with CMIP5 data. MAR and MAT for the period 1970-2005 and surface radiation for the period 1983-2005 were then compared with model outputs.

\section{e. Model fit and fit evaluation}

The variation of site MAR and site NPP and MAR and NPP from CMIP5 models was fitted with a power model, using the nonlinear least squares curve fitting package (available at http://purl.com/net/mpfit; Markwardt 2009) in the Interactive Data Language (IDL) (Fig. 1b). To determine the power model curve we used a bootstrap procedure with 5000 resamplings with replacements (Wilks 2006). The power model used in this study $\left(\mathrm{NPP}=\mathrm{c} 1 \times \mathrm{MAR}^{\mathrm{c} 2}\right)$ resembles the model presented in previous studies $\left(\mathrm{NPP}=\mathrm{c} 3 \times \mathrm{MAR}^{\mathrm{c} 4} / e^{\mathrm{c} 5} \times \mathrm{MAR}\right.$; Del Grosso et al. 2008; Schuur 2003). However, in those cases the denominator accounts for a decrease of NPP with an increase in MAR that was not observed in our data. These models produced similar results for most of the site data used in this study (Fig. S4 in the supplementary material). The fitted curve for site MAR and NPP was denoted by MAR-NPP ${ }_{\text {obs. }}$. Similarly, the fitted curve for MAR and NPP for a given CMIP5 model was denoted as MAR-NPP ${ }_{\text {CMIP5- } x}(x$ representing a given CMIP5 model). The power model characterizes an increase of NPP with rainfall that has been observed in many tropical forest sites. For instance, Amazonia observational studies have shown an east-west rainfall gradient (Negrón-Juárez et al. 2009; Sombroek 2001) coinciding with the east-west gradient of productivity (Aragão et al. 2009; Malhi and Davidson 2009; Malhi et al. 2004, 2011). However, NPP is also affected by soil characteristics, nutrients, temperature, radiation, biomass turnover times, and so forth (Aragão et al. 2009; Cleveland et al. 2011; Malhi 2012; Nemani et al. 2003; Phillips et al. 2004; Stephenson and van Mantgem 2005; Stephenson et al. 2011).

Since the coefficient of determination $r^{2}$ is not recommended for nonlinear models (Spiess and Neumeyer 2010), to evaluate the ability of MAR-NPP ${ }_{\text {obs }}$ and MAR-NPP CMIP5-x $_{\text {to }}$ to reproduce their respective data we used the root-mean-square error approximation (RMSEA; 
RMSEA $=\sqrt{\left(\chi^{2}-\mathrm{df}\right) / \mathrm{df}(N-1)}$, where $\mathrm{df}$ is the degree of freedom, $N$ is the number of data points, and $\chi^{2}$ is the chi-square value from data and fitted values) (Kelley and Lai 2011; Kenny et al. 2015; Steiger and Lind 1980). RMSEA values in the range (0-0.08) are considered from excellent to good fit, and RMSEA $\geq 0.08$ denotes that the model fit the data poorly (MacCallum et al. 1996).

\section{f. Benchmark metric}

Benchmarking, the evaluation of model performance against observations or defined standards, is useful to identify model strengths and to correct model deficiencies (Luo et al. 2012). In this study we used the observed relationship between MAR and NPP (Fig. 1b) as a benchmark for CMIP5 models. A number of studies have discussed in detail the performance of the CMIP5 models with respect to climate variables. In general, these studies show that the CMIP5 models underestimate rainfall and temperature (Kim et al. 2012; Kumar et al. 2013; Lewis and Karoly 2013; Yin et al. 2013) and overestimate surface downward shortwave radiation $(\mathrm{Li}$ et al. 2013; Wild et al. 2013). To avoid repetition, we performed a brief analysis between the climate datasets and the CMIP5 climate variables. However, since rainfall, temperature, and solar radiation covary (Liu et al. 2012; Richardson 1981; Trenberth and Shea 2005; Wilks 1999) and since rainfall has been observed to be a key climate control of NPP (Del Grosso et al. 2008; Schuur 2003), we considered rainfall to be the primary climate variable (Richardson 1981; Wilks 1999). To evaluate the comparability of observed climate and CMIP5 predictions we used the coefficient of determination: $r^{2}=\left[\sum_{i=1}^{N} w_{i}\left(M_{i}-\bar{M}\right)\left(C_{i}-\bar{C}\right)\right]^{2 /}$ $\sum_{i=1}^{N} w_{i}\left(M_{i}-\bar{M}\right)^{2} \sum_{i=1}^{N} w_{i}\left(C_{i}-\bar{C}\right)^{2}$. We also used the root-mean-square error: RMSE $=\sqrt{\sum_{i=1}^{N} w_{i}\left(M_{i}-C_{i}\right)^{2}}$, where $M_{i}$ and $C_{i}$ are the cell values from CMIP5 and the observed climate, respectively, in each cell $i, \bar{M}$ and $\bar{C}$ are the mean values, $w_{i}$ is the normalized $\left(\sum_{i=1}^{N} w_{i}=1\right)$ weight (area) of cell $i$, and $N$ is the number of cells (Table 1).

MAR-NPP ${ }_{\text {obs }}$ (Fig. 1b) and MAR-NPP CMIP5-x were compared using the RMSE: [RMSE = $\left.\sqrt{(1 / N) \sum_{i=1}^{N}\left(M_{i}-S_{i}\right)^{2}}\right]$, where $M_{i}$ represents MAR$\mathrm{NPP}_{\text {CMIP5- }}, S_{i}$ represents MAR-NPP ${ }_{\text {obs }}$, and $N$ is the number of verifying points. The RMSE was calculated for MAR between 1100 and $3500 \mathrm{~mm} \mathrm{yr}^{-1}$ (a range of MAR produced for most of the CMIP5 models) and used to rank the models. A rank $k$ from 1 to 10 (where 1 indicates the lowest and 10 indicates the greatest difference against observations) was assigned to each model. A similar rank was used for the CRU and CMIP5 rainfall comparison.

\section{Results}

\section{a. Site NPP and CMIP5 NPP}

Site NPP depends on the $c$ factor. Thus, we tested how the range of $c$ from 0.2 to 1.2 impacted the resulting observed site level NPP compared with the CMIP5 NPP. Statistical similarity between observed and model estimates was determined by a Student's $t$ statistic at the $95 \%$ confidence interval. A $c$ value of 0.2 produced a mean site NPP of $8.33 \pm 3.67 \mathrm{MgCha}^{-1} \mathrm{yr}^{-1}$ (mean \pm standard deviation), and only the CanESM2 and MIROC models produced significantly similar mean NPP values. A $c$ value of 0.6 produced a mean site NPP of $11.12 \pm 4.89$ $\mathrm{MgCha}^{-1} \mathrm{yr}^{-1}$, and in this case the BNU, CCSM4, CESM1, and GFDL models produced a significantly similar mean NPP value. A $c$ value of 0.9 yielded a mean site NPP of $13.20 \pm 5.81 \mathrm{MgCha}^{-1} \mathrm{yr}^{-1}$, and in this case the mean NPP from HadGEM2, IPSL, and MPI were statistically similar when compared with site NPP. A $c$ value of 1.2 produced a mean site NPP of $17.53 \pm$ $6.45 \mathrm{MgCha}^{-1} \mathrm{yr}^{-1}$, with HadGEM2, IPSL, and MPI models producing similar mean NPP. No $c$ values (between 0.2 and 1.2) produced site level NPP statistically similar to GISS NPP. Table S2 in the supplementary material shows a comparison of CMIP5 NPP and site NPP for different values of $c$. Differences between site NPP and CMIP5 NPP values (Fig. 2) may be related to the mismatch in spatial $\left(2.5^{\circ}\right.$ model cells are several orders of magnitude larger than site size) and temporal domains.

\section{b. Site and CMIP5 climate}

A comparison of site MAR and MAT and climate products (CRU and GPCC; base period 1970-2005) is shown in Fig. 3. A close match between site and CRU (or GPCC) data was not expected because of the differences in spatial coverage between sites ( $\leq 1 \mathrm{ha})$ and climate data cells $\left(0.5^{\circ}\right)$ as well as mismatching of timing. The results show that sites with MAR $<5000 \mathrm{~mm} \mathrm{yr}^{-1}$ agreed well with CRU MAR and GPCC MAR. However, sites with MAR $>5000 \mathrm{~mm}$ ( 21 of the 327 sites) were not well represented by CRU or GPCC. These sites may represent 1) atypical years with higher-thanaverage MAR rather than sites with measurements collected during a different climate pattern since no sites were installed prior to 1970 or 2) sites with local orographically induced rainfall maxima that are not captured in the coarse-resolution climate datasets. Site MAT and CRU MAT showed considerable differences for MAT $<25^{\circ} \mathrm{C}$ ( 78 of the 327 sites). However, a large fraction of tropical areas lack temperature station data (Harris et al. 2013; Jones et al. 2012), and the infilling method over those areas may produce inaccurate results in CRU temperatures (Harris et al. 2013). Despite 


\section{NPP (MgC ha $\left.{ }^{-1} \mathrm{yr}^{-1}\right)$}
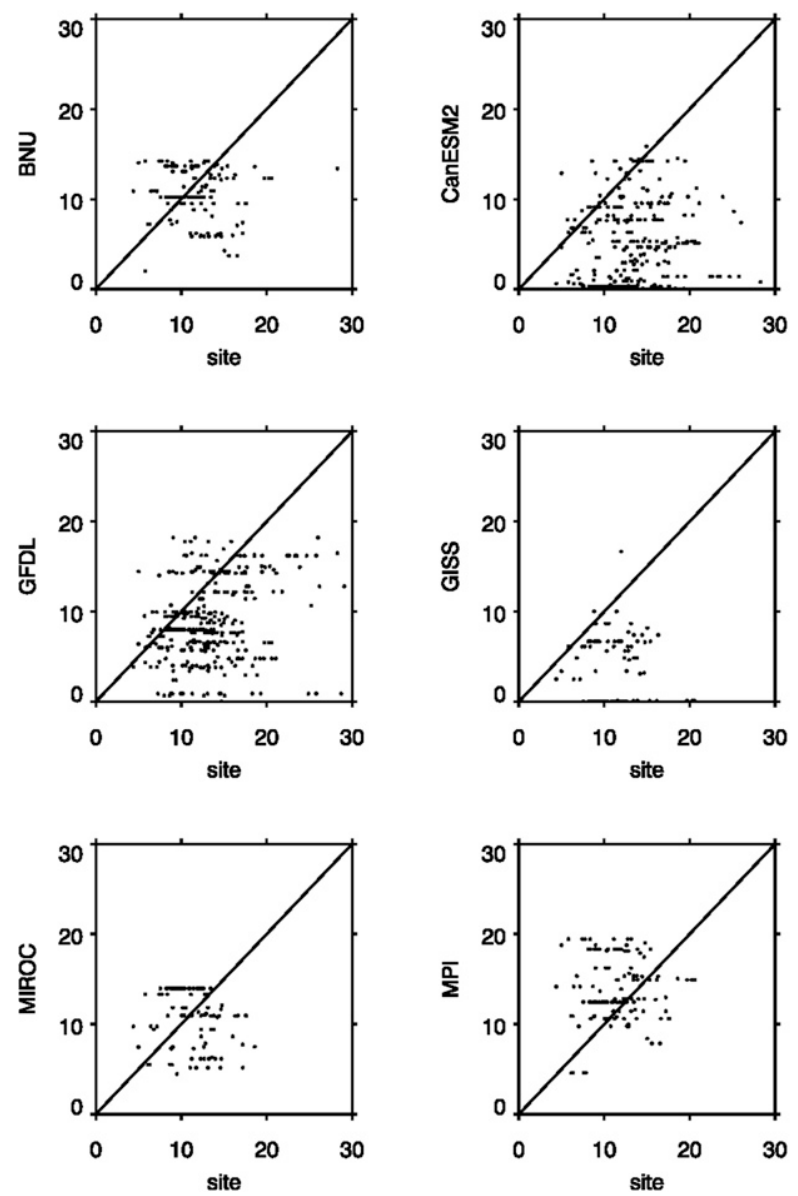

differences in spatial scale and temporal matching between sites and climate products, these results show that, in general, climate variables collected at sites were representative of the 1970-2005 climatology at each site. It suggests that the site NPP values were representative of the 1970-2005 climate. We found similar results when comparing MAR and MAT between the site and the CMIP5 models, respectively (Figs. S5 and S6 in the supplementary material).

A comparison of climate variables [MAR, MAT, and downward surface solar radiation, (DSSR)] between the CMIP5 and the CRU and SRB datasets are shown in Table 1 (and Fig. S7 in the supplementary material). The HadGEM2 model best captured the spatial pattern of MAR, followed by the GFDL models. The GISS model best reproduced MAT, followed by the CCSM4, CESM1, and IPSL models. Finally, all models poorly reproduced the DSSR, with the HadGEM2 and MIROC models performing better than the other models. In general, our results agreed with previous tropical forest studies that found that the HadGEM2 and CCSM4 models better
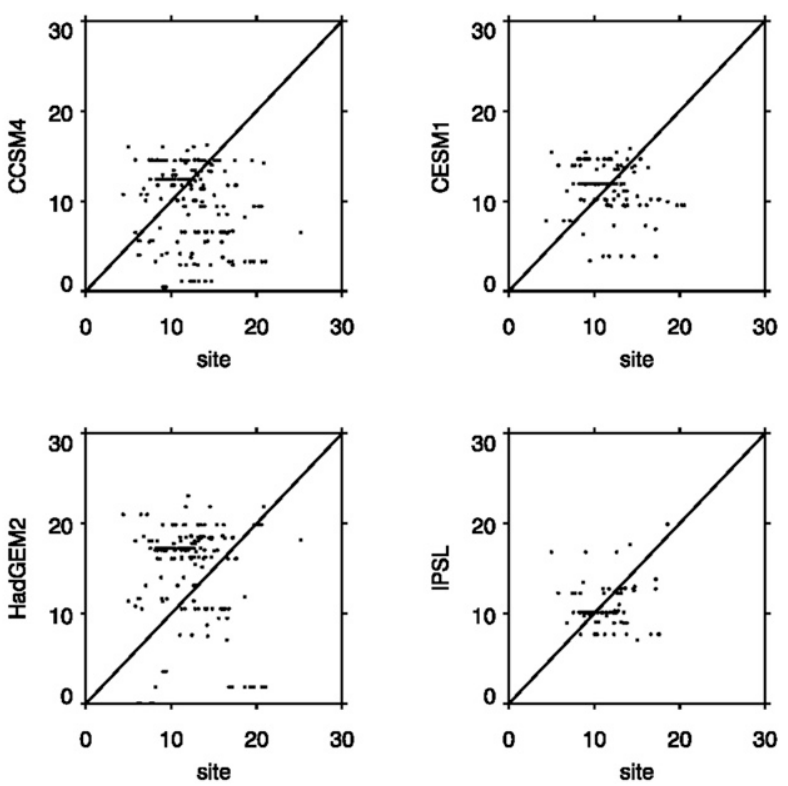

FIG. 2. Comparison of site-calculated NPP and CMIP5 NPP (period 1970-2005) for the CMIP5 models. The location (lat-lon) of each site was used to obtain the corresponding value from the models. The 1:1 line is shown.

represent annual rainfall as compared with the GFDL and IPSL (Yin et al. 2013) and the CanESM2 models (Jones and Carvalho 2013). Overall, the model performance with respect to MAT was expected to follow model performance of MAR (Kumar et al. 2013). Our results confirm this expectation. The poor performance of the CMIP5 model to reproduce DSSR was likely not associated with the SRB data used in this study because similar deficiencies were found when comparing CMIP5 and the radiation data from Energy Balanced and Filled (EBAF)surface and the International Satellite Cloud Climatology Project (ISCCP)-derived products ( $\mathrm{Li}$ et al. 2013).

No clear patterns between NPP and MAT in CMIP5 predictions were found (Fig. S8 in the supplementary material), which is consistent with other observational studies (Del Grosso et al. 2008; Schuur 2003). NPP and surface radiation in CMIP5 (Fig. S9 in the supplementary material) exhibited an opposite pattern to that of NPP and rainfall (Fig. 1b) with increases in NPP associated with decreases in radiation (except GISS; Fig. S9). 

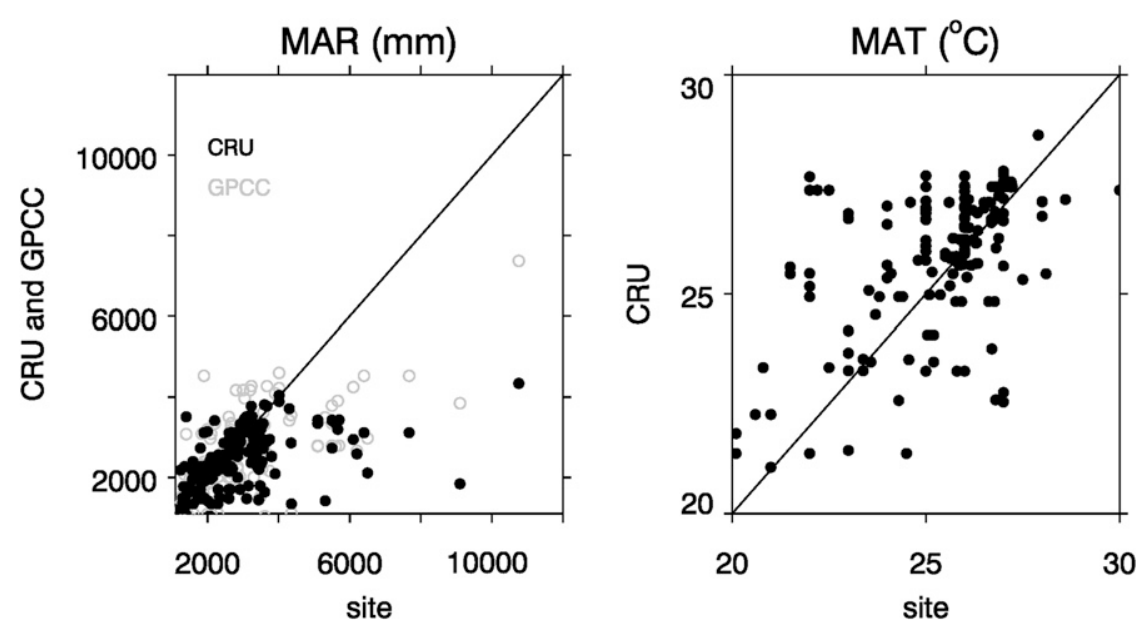

FIG. 3. Comparison of observed (left) MAR and (right) MAT from sites used in this study and the MAR and MAT (based period 1970-2005) values from CRU and GPCC data. Number of total sites is 327 .

\section{c. CMIP5 model performance}

The RMSEA for NPP-MAR ${ }_{\text {obs }}$ was 0.04. The RMSEA for NPP-MAR CMIP5- $x_{\text {for }} 7$ of the 10 models was $<0.08$, indicating that the power model properly represented the variation of MAR and NPP. The RMSEA for three models was greater than 0.1 (CanESM2, GISS, and IPSL), indicating poor fit. Variations in solar radiation with rainfall and NPP were also shown (Fig. 4). CMIP5 models did not reproduce the observed range of MAR, as expected if the higher values in the site-level data were due to local orographic forcing or anomalous years. NPP for a given MAR in the IPSL and MPI models were systematically higher than NPP-MAR ${ }_{\text {obs }}$. This characteristic may be related to an overestimation of tree cover, as has been reported for MPI (Brovkin et al. 2013a), or radiation produced in the IPSL models (Fig. 4). Using RMSE between NPP-MAR ${ }_{\text {obs }}$ and NPP-MAR - $_{\text {- }}$ MIP5-x as a benchmark metric of model performance the CMIP5 models ranked (from best to worst) as follows: GFDL, CESM1, CCSM4, BNU, MIROC, IPSL, MPI, HadGEM2, CanESM2, and GISS. This ranking holds for $c=0.71 \pm 0.08$. It should be noted that the RSME for the IPSL and MPI models was calculated with fewer data points because these models produced no MAR values greater than $\sim 3500 \mathrm{~mm} \mathrm{yr}^{-1}$. However, the model rank did not change when we used a MAR range from 1100 to $4000 \mathrm{~mm} \mathrm{yr}^{-1}$, but in this case the RMSE for the CESM1, IPSL, MIROC, and MPI models was calculated with fewer data points. The low performance of CanESM2 may be related to extremely (and unrealistically) low values of NPP over a large fraction of Amazonia (Fig. S10 in the supplementary material). The GISS model predicted tropical forested areas with negative NPP (Fig. S11 in the supplementary material) that were disregarded in our analysis since our site data had no negative NPP values.

\section{d. CMIP5 NPP projections}

Using historical simulations, all models (except GISS) predicted NPP values in the range of site NPP (using $c=$ $0.71 \pm 0.08$; Fig. 5a). The historical simulations showed that the model with lowest mean NPP was GISS followed by the CanESM2 model and the highest NPP was produced by MPI and HadGEM2. For the period 20062100 , a monotonic increase in NPP was projected in all models under RCP4.5 and RCP8.5, except for the RCP4.5 scenario in CanESM2, which maintained a relatively small decreasing trend (Fig. 5a). In the last few decades of the twenty-first century all models (except GISS for RCP8.5) projected a relative slowdown in NPP increases with respect to the trend projected earlier in the century. HadGEM2 predicted an end-of-century decrease in NPP compared to its peak around 2070; despite that, the HadGEM2-projected NPP values were still the highest among the models. MIROC was the only model that produced higher NPP in RCP4.5 than in RCP8.5, although just slightly so.

There appear to be three groups of end-of-century model NPP projections under RCP8.5. By 2100, RCP8.5 simulations from the HadGEM2, MPI, and IPSL models (the three largest projected increases) projected a mean tropical NPP of $19.2 \pm 1.1 \mathrm{MgCha}^{-1} \mathrm{yr}^{-1}$ (an increase of $62 \%$ with respect to current mean site NPP), an increase of $32 \% \pm 12 \%$ relative to the end of their historical simulations (2005). The GFDL, CESM1, CCSM4, and BNU models (models with intermediate projected increases) projected a mean NPP of $14.1 \pm 0.73 \mathrm{MgCha}^{-1} \mathrm{yr}^{-1}$ (an increase of $19 \%$ compared to mean site NPP), which 

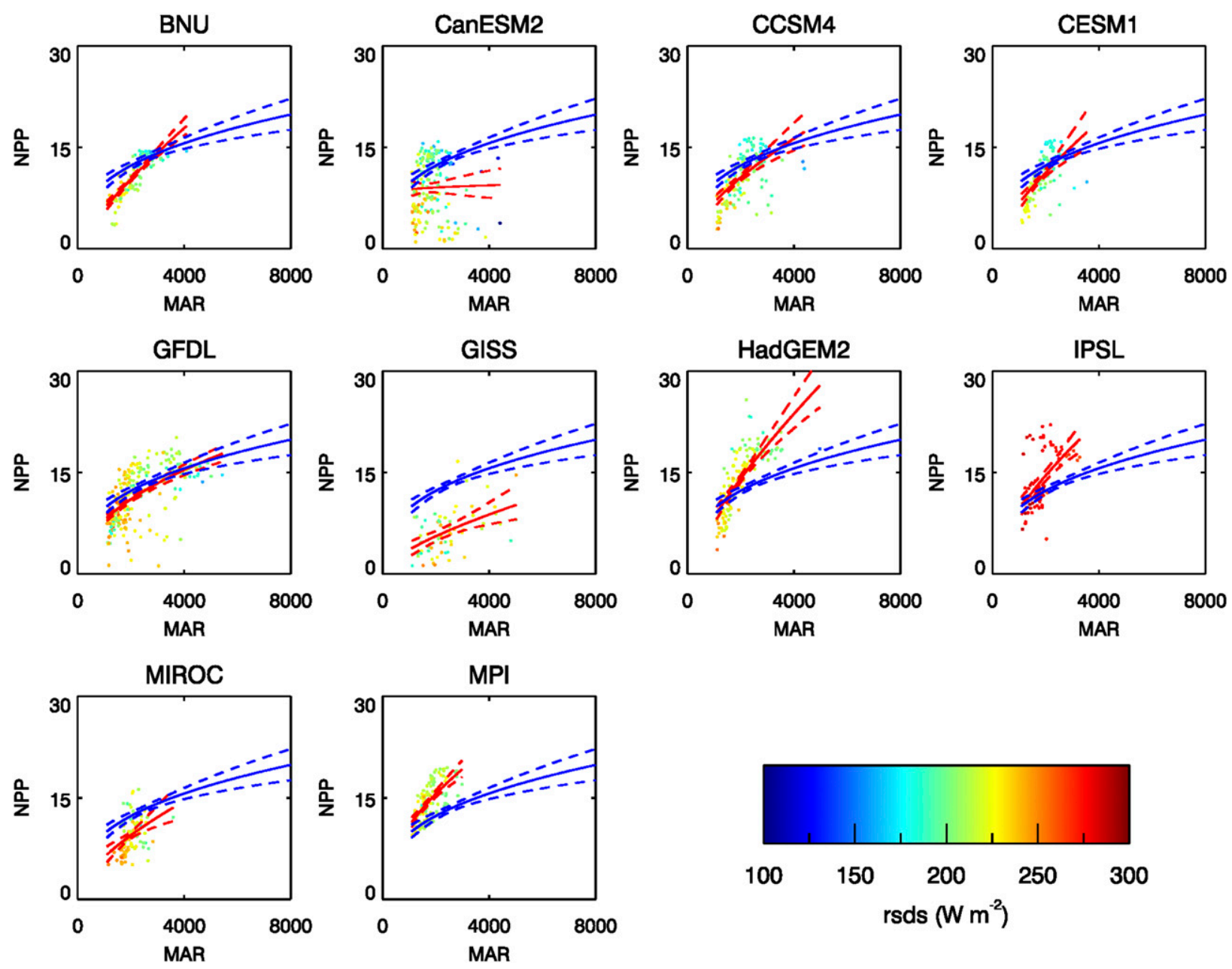

FIG. 4. Variations of NPP ( $\left.\mathrm{MgCha}^{-1} \mathrm{yr}^{-1}\right)$, MAR (mm), and RSDS ( $\mathrm{W} \mathrm{m}^{-2}$, colored dots) over tropical forests for the period 19702005 in the CMIP5 models. The red curve is the CMIP5 NPP-MAR fit for each model and the blue curve is the MAR-NPP ${ }_{\text {obs }}$ (Fig. 1b), which is the same in each subfigure. The dashed lines represent the 95\% confidence bands. The RMSE between these curves for MAR between 1100 and $3500 \mathrm{~mm} \mathrm{yr}^{-1}$, and the available range of MAR (IPSL and MPI), are shown in Table 1.

represents an increase of $25 \% \pm 14 \%$ relative to their historical simulations in 2005. The CanESM2 and MIROC models (the lowest projected fractional responses) projected a value of $9.2 \pm 2.8 \mathrm{MgCha}^{-1} \mathrm{yr}^{-1}$ (a decrease of $22 \%$ compared to site NPP), which represents an increase of $8 \% \pm 3 \%$ compared with their respective historical simulations. The GISS model projected a value of $12.5 \mathrm{MgCha}^{-1} \mathrm{yr}^{-1}$ (an increase of $5 \%$ relative to mean site NPP), which represents an increase of $178 \%$ with respect to the historical simulation in 2005.

For the RCP4.5 simulations, the HadGEM2, MPI, and IPSL models projected a mean NPP of $17.6 \pm$ $2.4 \mathrm{MgCha}^{-1} \mathrm{yr}^{-1}$ (an increase of $47 \%$ over site NPP) by 2100 , equivalent to an increase of $20 \% \pm 11 \%$ at the end of their historical simulations (2005). The CCSM4, BNU, CESM1, GFDL, and MIROC models projected very similar values of $12.12 \pm 0.39 \mathrm{MgCha}^{-1} \mathrm{yr}^{-1}$ (an increase of $\sim 2 \%$ over site NPP), or increases of $9 \% \pm 5 \%$ relative to their historical simulations (in 2005). The CanESM2 and GISS model projected a decrease of $4 \%$ and an increase of $35 \%$, respectively, compared with the end of their historical simulations. Thus, for RCP4.5 and RCP8.5, HadGEM2, IPSL, and MPI projected the highest increases in NPP relative to site NPP and the GISS model projected the highest relative change compared with the historical simulations.

In coupled simulations, the increase in NPP followed the increase in temperature (Fig. S12 in the supplementary material), which in turn is driven by increases in atmospheric $\mathrm{CO}_{2}$. Separation of the effects of only $\mathrm{CO}_{2}$ and only climate forcing on NPP showed that the increase in NPP was largely driven by $\mathrm{CO}_{2}$ fertilization, with climate forcing producing net decreases in NPP in all but one model (Fig. 5b). The only exception was the GISS model, which predicted (small) NPP decreases with 


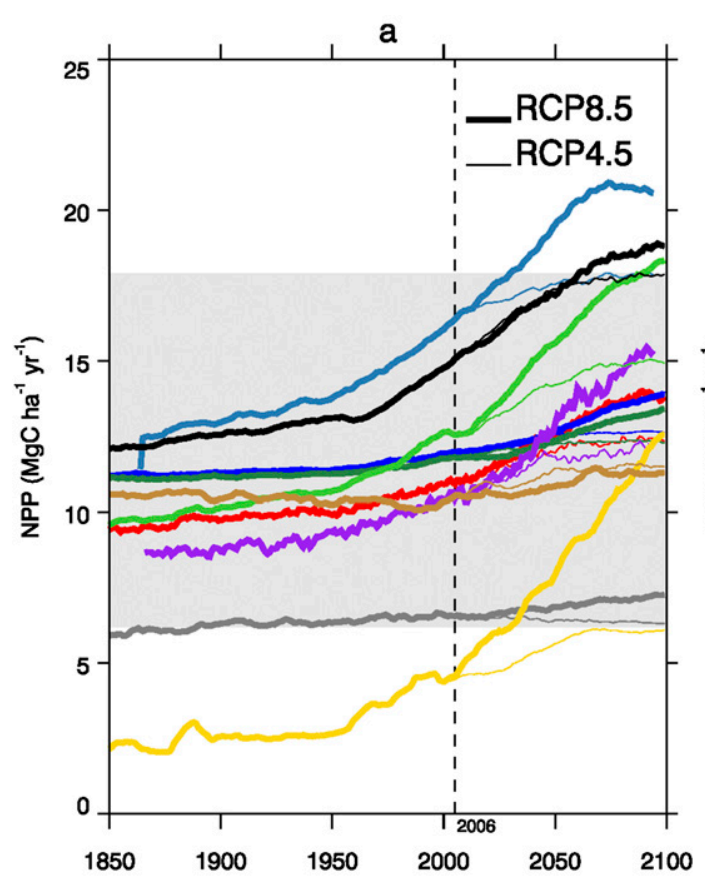

BNU CanESM2 CCSM4 CESM1 GFDL

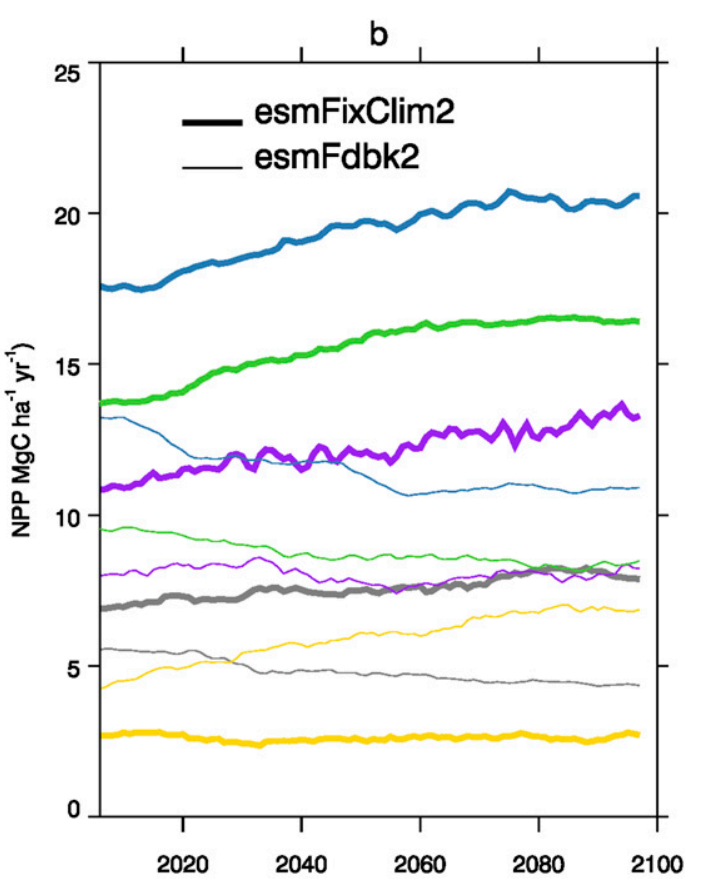

HadGEM2 IPSL MIROC MPI

FIG. 5. (a) Time series of historical and projected [RCP4.5 (thin lines) and RCP8.5 (thick lines)] NPP over tropical forests (Fig. 1a) for the CIMP5 models (colored lines). The gray area shows the range of present-day site NPP $\left(\mathrm{NPP}=11.8 \pm 5.5 \mathrm{MgCha}^{-1} \mathrm{yr}^{-1}\right.$; see section 2$)$. The vertical dashed line represents the year 2006 , the beginning of the projected simulation. (b) NPP projections due to climate change $\left(\mathrm{CO}_{2}\right.$ increase is hidden from the carbon cycle in esmFdbk2 experiments; thick lines) and $\mathrm{CO}_{2}$ fertilization $\left(\mathrm{CO}_{2}\right.$ increase is hidden from climate in esmFixClim2; thin lines) for the period 2006-2100. The esmFdbk2 simulations from 2006 to 2100 are available only for the CanESM2, GFDL, GISS, HadGEM2, and IPSL models.

$\mathrm{CO}_{2}$ increases and NPP increases with climate change (Fig. 5b). This model also projected increases in solar radiation associated with increases in rainfall (Fig. 4), in contrast to the other CMIP5 models and observations.

The monthly variation of the historical and RCP NPP and rainfall projections over tropical forests is shown in Fig. 6. The CRU showed lower rainfall from June to September, which was well reproduced by CMIP5 historical simulations in the CanESM2, CCMS4, CESM1, HadGEM2, and IPSL models, but the HadGEM2 model was the only model that closely reproduced the CRU values, while the CanESM2 model was significantly drier throughout the year. Except for GISS, all models underestimated present-day rainfall from January to May. During this period all models showed larger areas with rainfall $<100 \mathrm{~mm} \mathrm{month}^{-1}$ than those shown by CRU (Fig. S13 in the supplementary material). By the end of the year the models (except CanESM2) tended to produce similar or higher values than CRU rainfall. By the end of the twentyfirst century the RCP4.5 and RCP8.5 simulations produced rainfall close to the historical simulation but with different patterns across models: higher than historical simulations in CCSM4, GISS, IPSL, and MIROC; lower rainfall than historical simulations in CanESM2 and HadGEM2; and less seasonally variable rainfall in BNU, CESM1, GFSL, and MPI. CanESM2 and HadGEM2 predicted a longer dry season under RCP8.5. On the other hand, NPP increased from historical to RCP8.5 simulations for most models (except MIROC and CanESM2), but this increase appears to be lower from June to September (dry season; Fig. S14 in the supplementary material). All models (except HadGEM2) agreed on NPP seasonality at the end of the twenty-first century, with decreases in NPP during the dry season and lower values at the end of this season. The CanESM2 model had the lowest predicted NPP seasonality at the end of the twenty-first century. Under historical climate the phase between minimum rainfall and NPP varied from 1 to 3 months across models. Contrary to the other models, HadGEM2 predicted NPP increase during the beginning of the dry season resembling the gross ecosystem productivity (GEP) pattern observed (Restrepo-Coupe et al. 2013) in central Amazonia.

The use of esmFdbk2 simulations to determine the effect of climate forcing on the seasonality of rainfall 

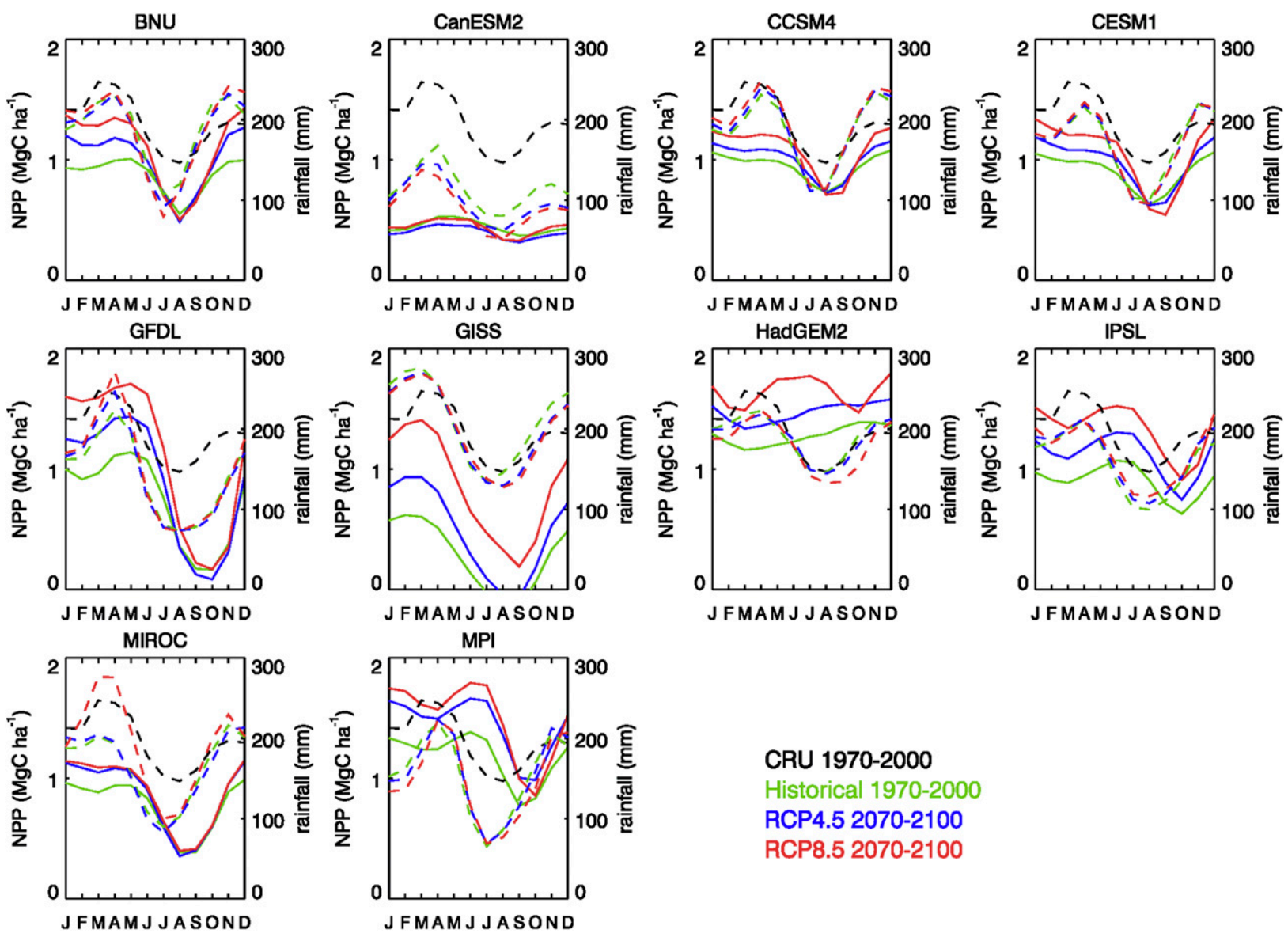

FIG. 6. The CMIP5 monthly variation in NPP and rainfall in tropical forests (Fig. 1) for historical (1970-2000) and RCP4.5 and RCP8.5 (2070-2100) simulations over tropical forests. The CRU rainfall (1970-2000) is also shown as reference. The NPP is shown in continuous lines and rainfall in dashed lines.

and NPP at the end of the twentieth and twenty-first centuries had contrasting patterns (Fig. 7). CMIP5projected esmFdbk2 rainfall was variable; CanESM2 and GFDL predicted higher rainfall at the end of the twenty-first century (with respect to present day), GISS and HadGEM2 predicted lower rainfall in the dry season and higher rainfall in the wet season, and IPSL predicted higher rainfall during the dry season. CMIP5 esmFdbk2 NPP models predicted (except GISS) lower NPP in the twenty-first century compared to present day, although the relative changes were different between the models. NPP seasonal cycles between the end of the twentieth and twenty-first centuries were also largely unchanged in these simulations, analogous to the fully coupled RCP simulations (Fig. 6).

The effect of climate forcing on NPP-MAR ${ }_{\text {CMIP5-x }}$ was investigated using the esmFdbk2 simulations for one decade at the end of the nineteenth, twentieth, and twenty-first centuries (Fig. 8). In all cases NPP increased with increasing MAR, except for the
CanESM2 in the 2090-99 period where NPP decreased with increasing MAR. The NPP-MAR CMIP5-CanESM2 $_{2}$

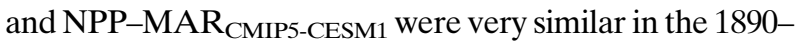
99 and 1990-99 periods. Over the 1990-99 period, and for the same MAR, the GFDL, HadGEM2, and IPSL models showed a higher NPP with respect to the period 1890-99, a characteristic that is more evident for MAR > $\sim 2000 \mathrm{~mm}$. For the period 2090-99 the CanESM2, GFDL, HadGEM2, and IPSL models showed lower NPP for all MAR with respect to the periods 1890-99 and 1990-99. In contrast, GISS was the only model that showed systematically higher NPP for a given MAR as time progressed. Thus, although tropical cover fraction is likely higher in the nineteenth than in the twentieth or twenty-first centuries (within the tropical forests areas analyzed here), the GFDL, HadGEM2, and IPSL models suggest that current climate is producing higher productivity for a given MAR than in the nineteenth century. The decrease of NPP for a given MAR in the 2090-99 period (except for GISS) can be related to 1 ) the decrease 

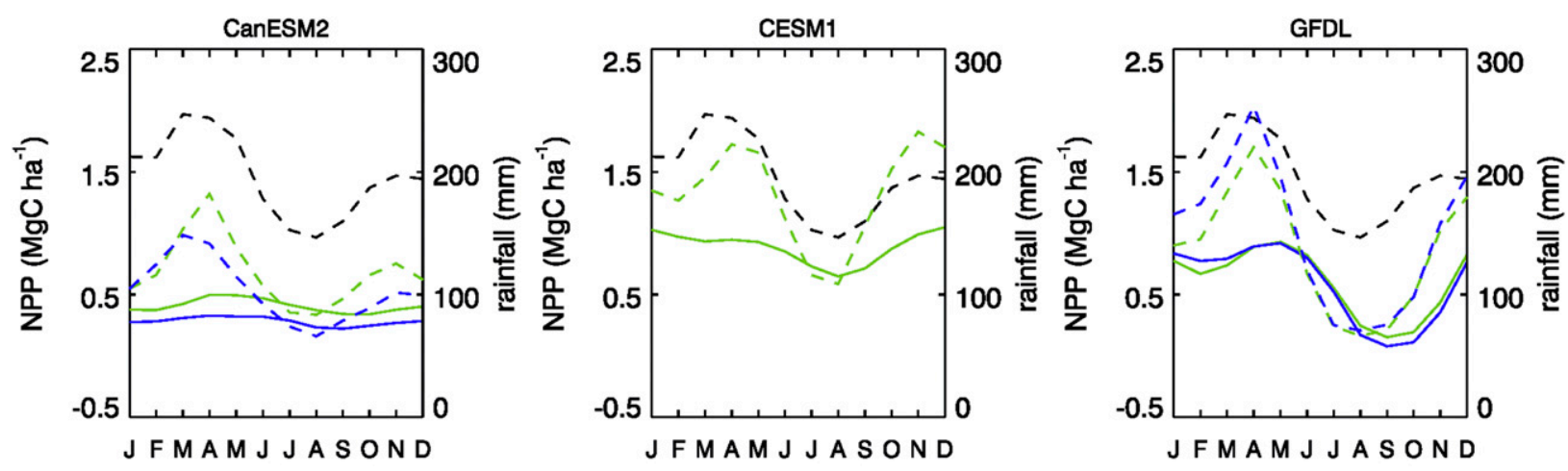

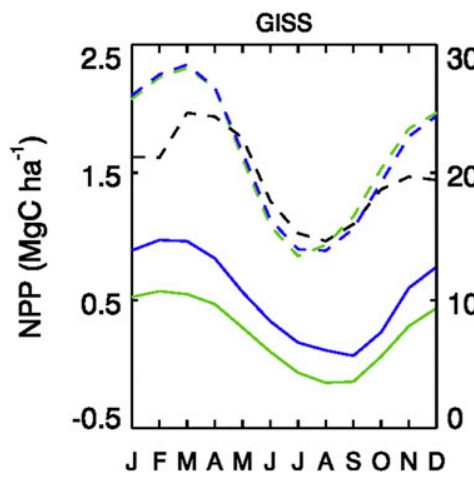

CRU $1970-2000$

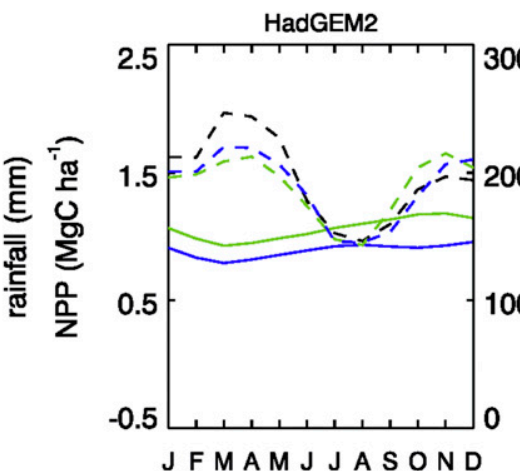

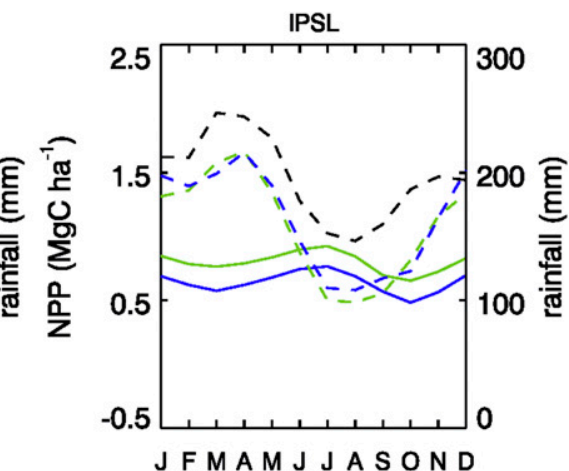

FIG. 7. Monthly variation of rainfall (dashed lines) and NPP (solid lines) from select CMIP5 models due to climate change (the carbon cycle does not respond to the increase in $\mathrm{CO}_{2}$ ) (esmFdbk2) for the period 1970-2000 and 2070-2100 over tropical forests. The monthly variation of CRU rainfall for the period 1970-2000 is shown as reference (dashed black line). The esmFdbk2 simulations were available for the CanESM2, CESM1 (up to 2005), GFDL, GISS, HadGEM2, and IPSL models.

in tropical cover fraction due to land-use and land-cover change (whose implementation varies from model to model (Brovkin et al. 2013b) (Fig. S15 in the supplementary material) and 2) increases in temperature.

\section{Discussion}

\section{a. Site NPP and models' ranks}

NPP is calculated as the sum of ANPP and belowground NPP (BNPP). ANPP includes NPP from the canopy, branches, stems, and emissions of volatile organic carbon compounds. BNPP includes NPP from fine roots, coarse roots, and exudates (the carbon loss through exudates and mycorrhizae) (Aragão et al. 2009). Observational assessments of all NPP components are hard to perform and biases (e.g., branch loss, loss of NPP to herbivores, decomposition before census) exist (Chambers et al. 2001; Malhi et al. 2011). Litterfall (canopy) and stem growth are commonly measured. Fine root production is not measured directly and all methods used in its estimation have serious limitations (Lukac 2012). The remaining components of NPP are frequently disregarded because of their small contribution or are assumed to be constant. It has therefore been suggested that our best measurements of NPP underestimate actual NPP (Malhi et al. 2011). The relative contributions of litterfall, stem growth, woody material (including stem, branch, and woody root production), and fine roots to NPP have been formulated (Aragão et al. 2009; Clark et al. 2001b; Malhi et al. 2011). Our NPP calculation is therefore reasonable because the proportion of these components may be relatively invariant in tropical forests (Aragão et al. 2009; Malhi et al. 2011). The approximation used in this study (NPP = ANPP $+c \times$ ANPP) is justified in cases where ANPP are available (Clark et al. 2001b). The approximation used to calculate site NPP with $c=0.71 \pm 0.08$ produced a mean site NPP $\left(11.8 \pm 5.5 \mathrm{MgCha}^{-1} \mathrm{yr}^{-1}\right)$ in line with observations over the lowland tropical forest (11.86 \pm $2.47 \mathrm{MgCha}^{-1} \mathrm{yr}^{-1}$ ) (Malhi et al. 2011). The variability of site NPP is consistent with other measurements of NPP 

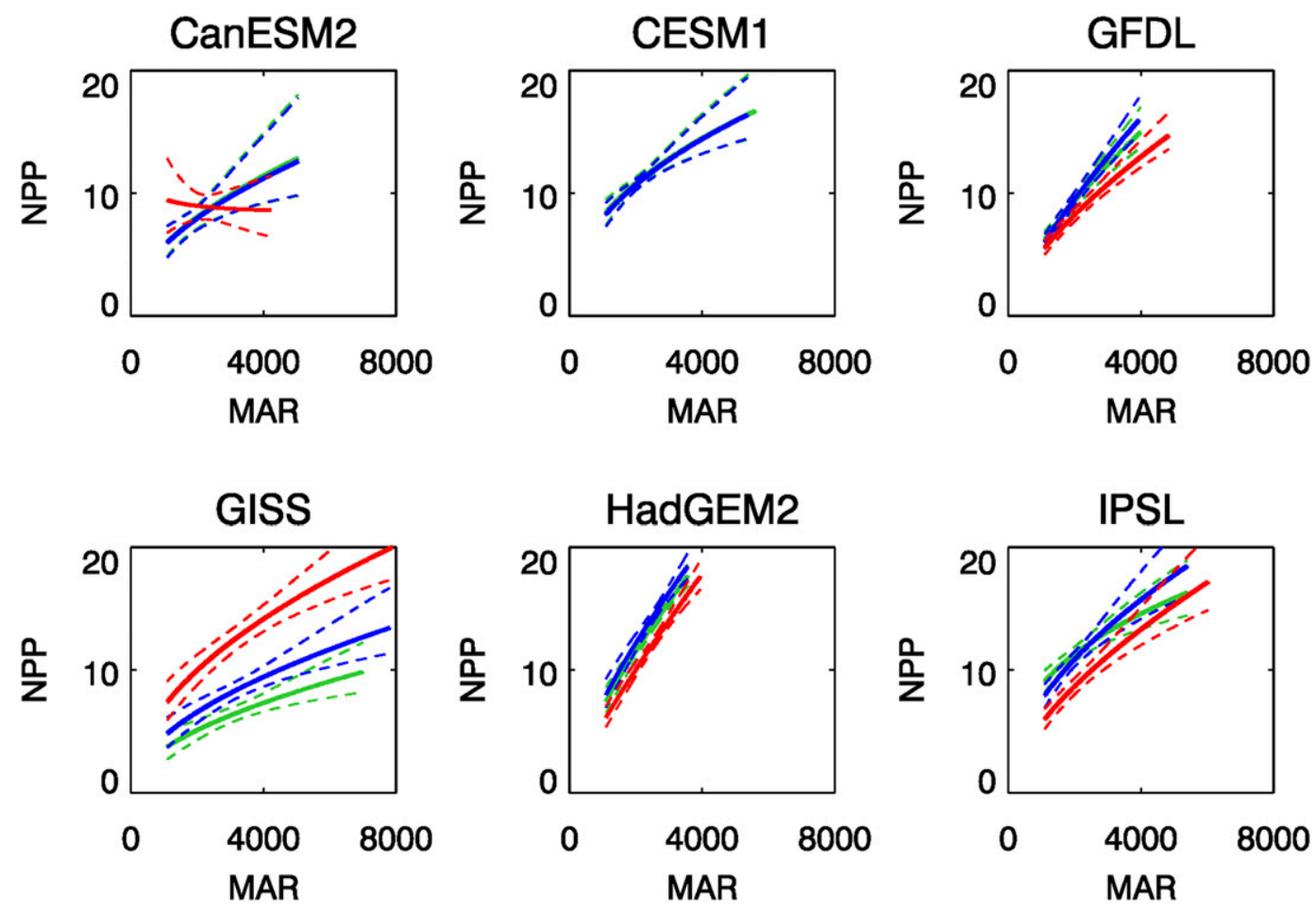

1890-1899

1990-1999

2090-2099

FIG. 8. The effect of climate change (esmFdbk2 simulation) on the NPP vs MAR relationships at the end of the nineteenth, twentieth, and twenty-first centuries (1890-1899, 1990-99, and 2090-99, respectively) for the CIMP5 models listed. Grid cells (as in Fig. 5) were not shown for clarity. The dashed lines represent the 95\% confidence bands. NPP is in megagrams of carbon per hectare per year and MAR is in millimeters.

not used in Malhi et al. (2011), as in Malaysia (13.72 $\mathrm{MgCha}^{-1} \mathrm{yr}^{-1}$ ) (Hossain et al. 2008). The models that better reproduced the mean site NPP (using $c=$ $0.71 \pm 0.08)$ were the GFDL, CESM1, CCSM4, and BNU models, and these models were consequently better ranked. Using $c=0.2$, model ranking (from best to worst) is CanESM2, MIROC, GISS, GFDL, CCSM4, CESM1, BNU, IPSL, MPI, and HadGEM2; however, a value of $c=0.2$ produced a relatively low mean NPP (with respect to observations). Using $c=0.9$, model ranking (from best to worst) is IPSL, MPI, CESM1, HadGEM2, GFDL, CCSM4, BNU, MIROC, CanESM2, and GISS. It should be noted that the IPSL and MPI models produced the shortest ranges of rainfall of all models (Fig. 5). The spatial variability of tropical forests suggests that $c$ would have a high variability. However, the assessment of this variability depends on the availability of observed data of NPP, which is currently limited. Nevertheless, the four models with higher ranks remain highly ranked for a range of $c$ values that produce mean site NPP close to current observations (Table S2).

\section{b. CMIP5 models' performance}

In this study we used a minimum threshold of MAR $\geq 1100 \mathrm{~mm}$ across tropical forests (Fig. S2). Over Amazonia Sombroek (2001) has reported a comparable value. This threshold was reproduced by all models (Fig. 5). In addition, most models reproduced MAR $\geq$ $4000 \mathrm{~mm}$, consistent with observations (Fig. S2). Thus, most models reproduced the observed range of MAR. However, all models had difficulty reproducing the spatial pattern of climate variables (the HadGEM2 model performed best compared to the other models) as discussed in other studies (Ahlström et al. 2012; Jones and Carvalho 2013; Mehran et al. 2014; Yin et al. 2013). With respect to the seasonal pattern of rainfall (Fig. 6 and Fig. S13), we found that CMIP5 models performed better over areas with a long dry season (4-5 months with rainfall $<100 \mathrm{~mm} \mathrm{month}^{-1}$; Sombroek 2001; Fig. S14). It would be worthwhile to analyze the temporal NPP variation, but observations of monthly NPP variation in tropical forest are scarce; thus, it is not clear how NPP responds to reduced rainfall during the dry 
season (Rowland et al. 2014). In general, studies on the limitations of CMIP5 models in reproducing components of the carbon cycle have been presented by others. These limitations have generally been associated with poor representation of land-use change (Anav et al. 2013; Friedlingstein et al. 2014), poor representation of rooting depth and LAI (Anav et al. 2013), and deficiencies in model reproduction of observed atmospheric $\mathrm{CO}_{2}$ levels (Friedlingstein et al. 2014; Hoffman et al. 2014; Keppel-Aleks et al. 2013), all of which affect NPP.

\section{c. CMIP5 NPP projections}

All CMIP5 models projected an increase of NPP by the end of 2100 compared to present NPP (Fig. 5). The direct physiological response of NPP to increases in atmospheric $\mathrm{CO}_{2}$ has been shown in a number of studies (Arora et al. 2013; Boer and Arora 2013; Friedlingstein et al. 2014). In all cases the CMIP5 NPP projections at 2100 appear to be influenced by the NPP values at the beginning of the projection simulations (year 2005). Thus, models with highest NPP during the end of the historical period projected the highest NPP and had the highest relative (with respect to the historical period) increase (except GISS). This characteristic may be a response to a similar behavior observed in the CMIP5 models with respect to atmospheric $\mathrm{CO}_{2}$ (Friedlingstein et al. 2014; Hoffman et al. 2014).

The rate of change in NPP projected over the twentyfirst century is variable among CMIP5 models, but a positive trend is dominantly driven by $\mathrm{CO}_{2}$ fertilization, except in the GISS model (Fig. 5). For RCP8.5, the highest increases in NPP relative to the end of the historical simulation were projected in HadGEM2, MPI, IPSL, GFDL, and GISS; moderate increases were projected in CCM4, BNU, and CESM1; and small increases were projected in MIROC and CanESM2. All models except HadGEM2 showed maximum NPP at the end of the twenty-first century consistent with the increase in atmospheric $\mathrm{CO}_{2}$ (Meinshausen et al. 2011); however, differences in the changes of NPP were observed across models. For instance, the HadGEM2 model projected the highest NPP by 2070, dropping its NPP projection after this year as a result of the loss of tropical forests (Good et al. 2011; Jones et al. 2009). Thus, changes in forests cover as well as the projected increase in $\mathrm{CO}_{2}$ have direct influence on projected NPP. A slowdown in the increase of NPP after 2050 was projected in RCP8.5 and RCP4.5, suggesting less productivity with increases in atmospheric $\mathrm{CO}_{2}$. The overall projected increase of NPP would increase the fixation of atmospheric $\mathrm{CO}_{2}$ through an increase of production in leaves, wood, and roots (DeLucia et al. 1999; Friedlingstein et al. 1999;
Li et al. 2015), but this increase varies across models (Li et al. 2015; Shao et al. 2013). However, the way in which the projected changes in NPP will affect the carbon sink in tropical forest ecosystems is difficult to evaluate within the context of this study given different effects, such as soil decomposition dynamics, that depend on temperature (Hou et al. 2013; Sayer et al. 2011; ToddBrown et al. 2013), allocation changes, and forest structure changes, which should be accounted for.

By isolating the effect of climate on NPP we found that climate change produces a decrease in NPP (except for the GISS model), but this signal is overwhelmed by the $\mathrm{CO}_{2}$ fertilization effect, which largely increases NPP (Fig. 5). The strongest fertilization effect was observed in the HadGEM2 and IPSL models and the weakest in the CanESM2 and GISS models. The decrease of NPP due to climate change (except GISS) may be related to a combination of factors, including the decrease in tropical land-cover fraction (Fig. S15) and the leaf photosynthesis approach used in CMIP5 models for $\mathrm{C}_{3}$ plants that decreases photosynthesis with increases in temperature. Decreases in rainfall would be another factor, but such a decrease was markedly evident only in the CanESM2 and GFDL models (Fig. 7). The decrease in NPP associated with an increase in temperature is consistent with the experimental studies carried out in Amazonia, which showed an increase in temperature leads to a decrease in photosynthesis (Doughty 2011).

Comparison of end of nineteenth- and twentiethcentury CMIP5 simulations suggests that current climate is promoting maximum productivity under current $\mathrm{CO}_{2}$ concentrations, as shown in three out of six models. The increase of NPP due to increased $\mathrm{CO}_{2}$ concentrations was produced by the fertilization effect (Norby et al. 2005) and was consistent with an increase in GPP (Arora et al. 2013). In general, our results show that the CMIP5 NPP tropical forest variability was highly sensitive to the increase of atmospheric $\mathrm{CO}_{2}$. Further studies should consider regional analysis. For instance, a recent observational study showed that wood production in Costa Rican tropical forests was strongly related to climate variation and not to $\mathrm{CO}_{2}$ fertilization (Clark et al. 2010, 2013). Thus, the simultaneous effects of rainfall, temperature, nutrients, and so forth on NPP in CMIP5 models remain to be explored.

Our study found that the HadGEM2 model best reproduced current temperature and rainfall over tropical forests. On the other hand, models with lower performance in reproducing climate had better performance reproducing the relationship between NPP and MAR. In addition, the CMIP5 models also revealed an association between NPP and solar radiation. All CMIP5 models (except GISS) showed decreases in solar radiation with 
increases in NPP and rainfall. Unfortunately, downward surface solar radiation at the surface is not commonly measured at the global scale, preventing us from confirming this finding. However, a similar pattern of NPP, rainfall, and radiation is found in Amazonia. In the Amazon, the observed east-west gradient in forest productivity coincides with the gradient in rainfall (Malhi and Davidson 2009). This east-west gradient in rainfall and productivity coincides with decreases in solar radiation at the surface, which result from increased cloud cover (Asner 2001) associated with convective systems.

\section{d. Final considerations}

Our study focused on the observed association between rainfall and NPP, which is only one component of many that affect the global terrestrial biogeochemical cycling. In addition, our model evaluation is sensitive to the available measurements of NPP. As acknowledged in this study (section 2), NPP is affected by factors besides rainfall, so it is important to analyze how CMIP5 models represent the effects of these factors on tropical NPP. For instance, tree mortality affects NPP (Malhi et al. 2015; Stephenson et al. 2011), yet models have limitations in accurately representing mortality (Negrón-Juárez et al. 2015). Therefore, metrics that simultaneously evaluate all components of the carbon cycle and the climate are needed. The development of these metrics is a growing research area (Anav et al. 2013; Luo et al. 2012; Randerson et al. 2009). A direct comparison of MAR and ANPP with similar variables from CMIP5 models would be desirable. However, at the time of this study most of the CMIP5 model outputs did not provide all components necessary to calculate ANPP. We suggest that future model intercomparison efforts include outputs to calculate NPP for leaf and wood as well as coarse and fine roots.

\section{Conclusions}

In this study we used the observed relationship of site NPP and rainfall over tropical forests to evaluate the performance of CMIP5 models. The relationship followed a power function with increases in NPP covarying with increases in rainfall. The ability of CMIP5 models in reproducing this relationship was calculated and used to rank their performance (from best to worst): GFDL, CESM1, CCSM4, BNU, MIROC, IPSL, MPI, HadGEM2, CanESM2, and GISS. Our ranking is partially subjective to quality and representativeness of observed NPP. Thus, metrics to evaluate model performance will depend on the available data for comparison. By the end of the twentyfirst century the four best models projected an increase in tropical NPP of about $25 \% \pm 14 \%$ under RCP8.5 with respect to historical simulations (2005), and an increase of about $19 \%$ with respect to site NPP. For RCP4.5, those models projected an increase of $9 \% \pm 5 \%$ with respect to historical simulations (2005) and an increase of about $2 \%$ with respect to site NPP. For RCP8.5 (and most RCP4.5) all models projected increases in NPP, but these increases occurred at different rates. Models with high NPP during the historical period projected the highest NPP at 2100 and had the highest relative (with respect to the historical period) increases. Seasonally, all CMIP5 models reasonably reproduced the observed pattern of rainfall, but the seasonality of NPP remains to be evaluated as a result of limited observational data. Nevertheless, by 2100 all models projected a seasonal pattern of rainfall and NPP similar to their historical simulations. CMIP5-projected tropical forest NPP was largely affected by $\mathrm{CO}_{2}$ fertilization, which largely increased projected NPP. Our study focused on the relationship between NPP and rainfall, so further studies addressing the individual and simultaneous effect of other climate variables on NPP are needed.

Acknowledgments. This research was supported by the Director of the Office of Science, Office of Biological and Environmental Research of the U.S. Department of Energy under Contract DE-AC02-05CH11231 as part of their Regional and Global Climate Modeling (RGCM) Program. We thank the three anonymous reviewers for their insightful comments and suggestions.

\section{REFERENCES}

Ahlström, A., G. Schurgers, A. Arneth, and B. Smith, 2012: Robustness and uncertainty in terrestrial ecosystem carbon response to CMIP5 climate change projections. Environ. Res. Lett., 7, 044008, doi:10.1088/1748-9326/7/4/044008.

Ainsworth, E. A., and S. P. Long, 2005: What have we learned from 15 years of free-air $\mathrm{CO}_{2}$ enrichment (FACE)? A meta-analytic review of the responses of photosynthesis, canopy properties and plant production to rising $\mathrm{CO}_{2}$. New Phytol., 165, 351-371, doi:10.1111/j.1469-8137.2004.01224.x.

Allison, I. B., and Coauthors, 2009: The Copenhagen Diagnosis, 2009: Updating the World on the Latest Climate Science. Climate Change Research Centre Rep., 60 pp. [Available online at http://www.copenhagendiagnosis.com/.]

Anav, A., and Coauthors, 2013: Evaluating the land and ocean components of the global carbon cycle in the CMIP5 Earth system models. J. Climate, 26, 6801-6843, doi:10.1175/ JCLI-D-12-00417.1.

Aragão, L. E. O. C., and Coauthors, 2009: Above- and belowground net primary productivity across ten Amazonian forests on contrasting soils. Biogeosciences, 6, 2759-2778, doi:10.5194/ bg-6-2759-2009.

Arora, V. K., and Coauthors, 2011: Carbon emission limits required to satisfy future representative concentration pathways of greenhouse gases. Geophys. Res. Lett., 38, L05805, doi:10.1029/2010GL046270. 
- , and Coauthors, 2013: Carbon-concentration and carbonclimate feedbacks in CMIP5 Earth system models. J. Climate, 26, 5289-5314, doi:10.1175/JCLI-D-12-00494.1.

Asner, G. P., 2001: Cloud cover in Landsat observations of the Brazilian Amazon. Int. J. Remote Sens., 22, 3855-3862, doi:10.1080/01431160010006926.

Boer, G. J., and V. K. Arora, 2013: Feedbacks in emission-driven and concentration-driven global carbon budgets. J. Climate, 26, 3326-3341, doi:10.1175/JCLI-D-12-00365.1.

Brovkin, V., L. Boysen, T. Raddatz, V. Gayler, A. Loew, and M. Claussen, 2013a: Evaluation of vegetation cover and landsurface albedo in MPI-ESM CMIP5 simulations. J. $A d v$. Model. Earth Syst., 5, 48-57, doi:10.1029/2012MS000169.

, and Coauthors, 2013b: Effect of anthropogenic land-use and land-cover changes on climate and land carbon storage in CMIP5 projections for the twenty-first century. J. Climate, 26, 6859-6881, doi:10.1175/JCLI-D-12-00623.1.

Burke, E. J., C. D. Jones, and C. D. Koven, 2013: Estimating the permafrost-carbon climate response in the CMIP5 climate models using a simplified approach. J. Climate, 26, 4897-4909, doi:10.1175/JCLI-D-12-00550.1.

Chambers, J. Q., and W. L. Silver, 2004: Some aspects of ecophysiological and biogeochemical responses of tropical forests to atmospheric change. Philos. Trans. Roy. Soc. London, 359B, 463-476, doi:10.1098/rstb.2003.1424.

—, J. dos Santos, R. J. Ribeiro, and N. Higuchi, 2001: Tree damage, allometric relationships, and above-ground net primary production in central Amazon forest. For. Ecol. Manage., 152, 73-84, doi:10.1016/S0378-1127(00)00591-0.

Chapin, F. S., III, P. A. Matson, and H. A. Mooney, 2003: Principles of Terrestrial Ecosystem Ecology. Springer, 847 pp.

Ciais, P., and Coauthors, 2011: The carbon balance of Africa: Synthesis of recent research studies. Philos. Trans. Roy. Soc. London, 369A, 2038-2057, doi:10.1098/rsta.2010.0328.

Clark, D. A., S. Brown, D. W. Kicklighter, J. Q. Chambers, J. R. Thomlinson, and J. Ni, 2001a: Measuring net primary production in forests: Concepts and field methods. Ecol. Appl., 11, 356-370, doi:10.1890/1051-0761(2001)011[0356:MNPPIF]2.0.CO;2.

$-,-,-\longrightarrow,-,-$, and E. A. Holland, 2001b: Net primary production in tropical forests: An evaluation and synthesis of existing field data. Ecol. Appl., 11, 371-384, doi:10.1890/1051-0761(2001)011[0371:NPPITF]2.0.CO;2.

, D. B. Clark, and S. F. Oberbauer, 2013: Field-quantified responses of tropical rainforest aboveground productivity to increasing $\mathrm{CO}_{2}$ and climatic stress, 1997-2009. J. Geophys. Res. Biogeosci., 118, 783-794, doi:10.1002/jgrg.20067.

Clark, D. B., D. A. Clark, and S. F. Oberbauer, 2010: Annual wood production in a tropical rain forest in NE Costa Rica linked to climatic variation but not to increasing $\mathrm{CO}_{2}$. Global Change Biol., 16, 747-759, doi:10.1111/j.1365-2486.2009.02004.x.

Cleveland, C. C., and Coauthors, 2011: Relationships among net primary productivity, nutrients and climate in tropical rain forest: A pan-tropical analysis. Ecol. Lett., 14, 939-947, doi:10.1111/j.1461-0248.2011.01658.x.

_ production in the terrestrial biosphere. Proc. Natl. Acad. Sci. USA, 110, 12 733-12 737, doi:10.1073/pnas.1302768110.

Collins, W. J., and Coauthors, 2011: Development and evaluation of an Earth-system model-HadGEM2. Geosci. Model Dev., 4, 1051-1075, doi:10.5194/gmd-4-1051-2011.

Del Grosso, S., W. Parton, T. Stohlgren, D. Zheng, D. Bachelet, S. Prince, K. Hibbard, and R. Olson, 2008: Global potential net primary production predicted from vegetation class, precipitation, and temperature. Ecology, 89, 2117-2126, doi:10.1890/07-0850.1.

DeLucia, E. H., and Coauthors, 1999: Net primary production of a forest ecosystem with experimental $\mathrm{CO}_{2}$ enrichment. Science, 284, 1177-1179, doi:10.1126/science.284.5417.1177.

Delworth, T. L., and Coauthors, 2006: GFDL's CM2 global coupled climate models. Part I: Formulation and simulation characteristics. J. Climate, 19, 643-674, doi:10.1175/JCLI3629.1.

Doughty, C. E., 2011: An in situ leaf and branch warming experiment in the Amazon. Biotropica, 43, 658-665, doi:10.1111/ j.1744-7429.2010.00746.x.

_ _ and Coauthors, 2014: The production, allocation and cycling of carbon in a forest on fertile terra preta soil in eastern Amazonia compared with a forest on adjacent infertile soil. Plant Ecol. Diversity, 7, 41-53, doi:10.1080/17550874.2013.798367.

Dufresne, J. L., and Coauthors, 2013: Climate change projections using the IPSL-CM5 Earth system model: From CMIP3 to CMIP5. Climate Dyn., 40, 2123-2165, doi:10.1007/s00382-012-1636-1.

Dunne, J. P., and Coauthors, 2012: GFDL's ESM2 global coupled climate-carbon Earth system models. Part I: Physical formulation and baseline simulation characteristics. J. Climate, $\mathbf{2 5}$, 6646-6665, doi:10.1175/JCLI-D-11-00560.1.

_ , and Coauthors, 2013: GFDL's ESM2 global coupled climatecarbon Earth system models. Part II: Carbon system formulation and baseline simulation characteristics. J. Climate, 26, 2247-2267, doi:10.1175/JCLI-D-12-00150.1.

Friedl, M. A., D. Sulla-Menashe, B. Tan, A. Schneider, N. Ramankutty, A. Sibley, and X. Huang, 2010: MODIS Collection 5 global land cover: Algorithm refinements and characterization of new datasets. Remote Sens. Environ., 114, 168-182, doi:10.1016/ j.rse.2009.08.016.

Friedlingstein, P., G. Joel, C. B. Field, and I. Y. Fung, 1999: Toward an allocation scheme for global terrestrial carbon models. Global Change Biol., 5, 755-770, doi:10.1046/j.1365-2486.1999.00269.x.

_ M. Meinshausen, V. K. Arora, C. D. Jones, A. Anav, S. K. Liddicoat, and R. Knutti, 2014: Uncertainties in CMIP5 climate projections due to carbon cycle feedbacks. J. Climate, 27, 511-526, doi:10.1175/JCLI-D-12-00579.1.

Gatti, L. V., and Coauthors, 2014: Drought sensitivity of Amazonian carbon balance revealed by atmospheric measurements. Nature, 506, 76-80, doi:10.1038/nature12957.

Gent, P. R., and Coauthors, 2011: The Community Climate System Model version 4. J. Climate, 24, 4973-4991, doi:10.1175/ 2011JCLI4083.1.

Giorgetta, M. A., and Coauthors, 2013: Climate and carbon cycle changes from 1850 to 2100 in MPI-ESM simulations for the Coupled Model Intercomparison Project phase 5. J. Adv. Model. Earth Syst., 5, 572-597, doi:10.1002/ jame.20038.

Girardin, C. A. J., and Coauthors, 2010: Net primary productivity allocation and cycling of carbon along a tropical forest elevational transect in the Peruvian Andes. Global Change Biol., 16, 3176-3192, doi:10.1111/j.1365-2486.2010.02235.x.

Good, P., C. Jones, J. Lowe, R. Betts, B. Booth, and C. Huntingford, 2011: Quantifying environmental drivers of future tropical forest extent. J. Climate, 24, 1337-1349, doi:10.1175/ 2010JCLI3865.1.

Harris, I., P. D. Jones, T. J. Osborn, and D. H. Lister, 2013: Updated high-resolution grids of monthly climatic observations-The CRU TS3.10 dataset. Int. J. Climatol., 34, 623-642, doi:10.1002/ joc.3711.

Hoffman, F. M., and Coauthors, 2014: Causes and implications of persistent atmospheric carbon dioxide biases in Earth system 
models. J. Geophys. Res. Biogeosci., 119, 141-162, doi:10.1002/ 2013JG002381.

Hossain, M., S. Othman, J. S. Bujang, and M. Kusnan, 2008: Net primary productivity of Bruguiera parviflora (Wight \& Arn.) dominated mangrove forest at Kuala Selangor, Malaysia. For. Ecol. Manage., 255, 179-182, doi:10.1016/j.foreco.2007.09.011.

Hou, S., L. Lei, and Z. Zeng, 2013: The response of global net primary productivity (NPP) to $\mathrm{CO}_{2}$ increasing and climate change: Evaluation of coupled model simulations. J. Food Agric. Environ., 11, 937-944.

Hurrell, J. W., and Coauthors, 2013: The Community Earth System Model: A framework for collaborative research. Bull. Amer. Meteor. Soc., 94, 1339-1360, doi:10.1175/BAMS-D-12-00121.1.

IPCC, 2013: Climate Change 2013: The Physical Science Basis Cambridge University Press, $1535 \mathrm{pp}$.

Jones, C., and L. M. V. Carvalho, 2013: Climate change in the South American monsoon system: Present climate and CMIP5 projections. J. Climate, 26, 6660-6678, doi:10.1175/JCLI-D-12-00412.1.

- J. Lowe, S. Liddicoat, and R. Betts, 2009: Committed terrestrial ecosystem changes due to climate change. Nat. Geosci., 2, 484-487, doi:10.1038/ngeo555.

Jones, P. D., D. H. Lister, T. J. Osborn, C. Harpham, M. Salmon, and C. P. Morice, 2012: Hemispheric and large-scale landsurface air temperature variations: An extensive revision and an update to 2010. J. Geophys. Res., 117, D05127, doi:10.1029/ 2011JD017139.

Kelley, K., and K. Lai, 2011: Accuracy in parameter estimation for the root mean square error of approximation: Sample size planning for narrow confidence intervals. Multivar. Behav. Res., 46, 1-32, doi:10.1080/00273171.2011.543027.

Kenny, D. A., B. Kanishan, and D. B. McCoach, 2015: The performance of RMSEA in models with small degrees of freedom. Sociol. Methods Res., 44, 486-507, doi:10.1177/ 0049124114543236.

Keppel-Aleks, G., and Coauthors, 2013: Atmospheric carbon dioxide variability in the community Earth system model: Evaluation and transient dynamics during the twentieth and twenty-first centuries. J. Climate, 26, 4447-4475, doi:10.1175/ JCLI-D-12-00589.1.

Kim, H.-M., P. J. Webster, and J. A. Curry, 2012: Evaluation of short-term climate change prediction in multi-model CMIP5 decadal hindcasts. Geophys. Res. Lett., 39, L10701, doi:10.1029/ 2012GL051644.

Kumar, S., V. Merwade, J. L. Kinter, and D. Niyogi, 2013: Evaluation of temperature and precipitation trends and long-term persistence in CMIP5 twentieth-century climate simulations. J. Climate, 26, 4168-4185, doi:10.1175/JCLI-D-12-00259.1.

Lacis, A. A., G. A. Schmidt, D. Rind, and R. A. Ruedy, 2010: Atmospheric $\mathrm{CO}_{2}$ : Principal control knob governing Earth's temperature. Science, 330, 356-359, doi:10.1126/science.1190653.

Lewis, S. C., and D. J. Karoly, 2013: Evaluation of historical diurnal temperature range trends in CMIP5 models. J. Climate, 26, 9077-9089, doi:10.1175/JCLI-D-13-00032.1.

Lewis, S. L., and Coauthors, 2009: Increasing carbon storage in intact African tropical forests. Nature, 457, 1003-1006, doi:10.1038/ nature 07771.

Li, J. L. F., D. E. Waliser, G. Stephens, S. Lee, T. L'Ecuyer, S. Kato, N. Loeb, and H.-Y. Ma, 2013: Characterizing and understanding radiation budget biases in CMIP3/CMIP5 GCMs, contemporary GCM, and reanalysis. J. Geophys. Res., 118 8166-8184, doi:10.1002/jgrd.50378.

Li, S., S. Lü, Y. Zhang, Y. Liu, Y. Gao, and Y. Ao, 2015: The change of global terrestrial ecosystem net primary productivity (NPP) and its response to climate change in CMIP5. Theor. Appl. Climatol., 121, 319-335, doi:10.1007/s00704-014-1242-8.

Liu, C., R. P. Allan, and G. J. Huffman, 2012: Co-variation of temperature and precipitation in CMIP5 models and satellite observations. Geophys. Res. Lett., 39, L13803, doi:10.1029/ 2012GL052093.

Loveland, T. R., and A. S. Belward, 1997: The IGBP-DIS global $1 \mathrm{~km}$ land cover data set, DISCover: First results. Int. J. Remote Sens., 18, 3289-3295, doi:10.1080/014311697217099.

Lukac, M., 2012: Fine root turnover. Measuring Roots: An Updated Approach, S. Mancuso, Ed., Springer, 363-373

Luo, Y., and Coauthors, 2008: Modeled interactive effects of precipitation, temperature, and $\left[\mathrm{CO}_{2}\right]$ on ecosystem carbon and water dynamics in different climatic zones. Global Change Biol., 14, 1986-1999, doi:10.1111/j.1365-2486.2008.01629.x.

_, and Coauthors, 2012: A framework for benchmarking land models. Biogeosciences, 9, 3857-3874, doi:10.5194/ bg-9-3857-2012.

MacCallum, R. C., M. W. Browne, and H. M. Sugawara, 1996: Power analysis and determination of sample size for covariance structure modeling. Psychol. Methods, 1, 130-149, doi:10.1037/1082-989X.1.2.130.

Malhi, Y., 2012: The productivity, metabolism and carbon cycle of tropical forest vegetation. J. Ecol., 100, 65-75, doi:10.1111/ j.1365-2745.2011.01916.x.

— , and E. A. Davidson, 2009: Biogeochemistry and ecology of terrestrial ecosystem of Amazonia. Amazonia and Global Change, M. Keller et al., Eds., Amer. Geophys. Union, 293-297.

, and Coauthors, 2004: The above-ground coarse wood productivity of 104 Neotropical forest plots. Global Change Biol., 10, 563-591, doi:10.1111/j.1529-8817.2003.00778.x.

, and Coauthors, 2009: Exploring the likelihood and mechanism of a climate-change-induced dieback of the Amazon rainforest. Proc. Natl. Acad. Sci. USA, 106, 20 610-20615, doi:10.1073/pnas.0804619106.

C. Doughty, and D. Galbraith, 2011: The allocation of ecosystem net primary productivity in tropical forests. Philos. Trans. Roy. Soc. London, 366B, 3225-3245, doi:10.1098/ rstb.2011.0062.

- , and Coauthors, 2015: The linkages between photosynthesis, productivity, growth and biomass in lowland Amazonian forests. Global Change Biol., 21, 2283-2295, doi:10.1111/ gcb.12859.

Markwardt, C. B., 2009: Non-linear least squares fitting in IDL with MPFIT. Proc. Astronomical Data Analysis Software and Systems XVIII, Quebec City, QC, Canada, ASP Conference Series, 251-254.

Martin, G. M., and Coauthors, 2011: The HadGEM2 family of Met Office Unified Model climate configurations. Geosci. Model Dev., 4, 723-757, doi:10.5194/gmd-4-723-2011.

Medlyn, B. E., 2011: Comment on "Drought-induced reduction in global terrestrial net primary production from 2000 through 2009." Science, 333, doi:10.1126/science.1199048.

Mehran, A., A. AghaKouchak, and T. J. Phillips, 2014: Evaluation of CMIP5 continental precipitation simulations relative to satellite-based gauge-adjusted observations. J. Geophys. Res. Atmos., 119, 1695-1707, doi:10.1002/ 2013JD021152.

Meinshausen, M., and Coauthors, 2011: The RCP greenhouse gas concentrations and their extensions from 1765 to 2300. Climatic Change, 109, 213-241, doi:10.1007/ s10584-011-0156-z. 
Milly, P. C. D., and Coauthors, 2014: An enhanced model of land water and energy for global hydrologic and Earth-system studies. J. Hydrometeor., 15, 1739-1761, doi:10.1175/JHM-D-13-0162.1.

Negrón-Juárez, R., W. Li, R. Fu, K. Fernandes, and A. O. Cardoso, 2009: Comparison of precipitation datasets over the tropical South American and African continents. J. Hydrometeor., 10, 289-299, doi:10.1175/2008JHM1023.1.

— C. Koven, W. Riley, R. Knox, and J. Chambers, 2015: Observed allocations of productivity and biomass, and turnover times in tropical forests are not accurately represented in CMIP5 Earth system models. Environ. Res. Lett., 10, 064017, doi:10.1088/1748-9326/10/6/064017.

Nemani, R. R., C. D. Keeling, H. Hashimoto, W. M. Jolly, S. C. Piper, C. J. Tucker, R. B. Myneni, and S. W. Running, 2003: Climate-driven increases in global terrestrial net primary production from 1982 to 1999. Science, 300, 1560-1563, doi:10.1126/science.1082750.

NOAA, 2014: Atmospheric $\mathrm{CO}_{2}$. NOAA, accessed 1 October 2014. [Available online at http://www.esrl.noaa.gov/gmd/ccgg/ trends/.]

Norby, R. J., and Coauthors, 2005: Forest response to elevated $\mathrm{CO}_{2}$ is conserved across a broad range of productivity. Proc. Natl. Acad. Sci. USA, 102, 18 052-18 056, doi:10.1073/ pnas.0509478102.

Oleson, K. W., and Coauthors, 2010: Technical description of version 4.0 of the Community Land Model (CLM). NCAR Tech. Note NCAR/TN-478+STR, 257 pp. [Available online at http://www.cesm.ucar.edu/models/cesm1.0/clm/CLM4_ Tech_Note.pdf.]

Phillips, O. L., and Coauthors, 2004: Pattern and process in Amazon tree turnover, 1976-2001. Philos. Trans. Roy. Soc. London, 359B, 381-407, doi:10.1098/rstb.2003.1438.

Quesada, C. A., and Coauthors, 2012: Basin-wide variations in Amazon forest structure and function are mediated by both soils and climate. Biogeosciences, 9, 2203-2246, doi:10.5194/ bg-9-2203-2012.

Randerson, J. T., and Coauthors, 2009: Systematic assessment of terrestrial biogeochemistry in coupled climate-carbon models. Global Change Biol., 15, 2462-2484, doi:10.1111/ j.1365-2486.2009.01912.x.

Restrepo-Coupe, N., and Coauthors, 2013: What drives the seasonality of photosynthesis across the Amazon basin? A crosssite analysis of eddy flux tower measurements from the Brasil flux network. Agric. Forest Meteor., 182-183, 128-144, doi:10.1016/ j.agrformet.2013.04.031.

Richardson, C. W., 1981: Stochastic simulation of daily precipitation, temperature, and solar radiation. Water Resour. Res., 17, 182-190, doi:10.1029/WR017i001p00182.

Rowland, L., and Coauthors, 2014: Evidence for strong seasonality in the carbon storage and carbon use efficiency of an Amazonian forest. Global Change Biol., 20, 979-991, doi:10.1111/ gcb. 12375 .

Samanta, A., M. H. Costa, E. L. Nunes, S. A. Vieira, L. Xu, and R. B. Myneni, 2011: Comment on "Drought-induced reduction in global terrestrial net primary production from 2000 through 2009." Science, 333, doi:10.1126/science.1199048.

Sayer, E. J., M. S. Heard, H. K. Grant, T. R. Marthews, and E. V. J. Tanner, 2011: Soil carbon release enhanced by increased tropical forest litterfall. Nat. Climate Change, 1, 304-307, doi:10.1038/nclimate1190.

Schmidt, G. A., and Coauthors, 2014: Configuration and assessment of the GISS ModelE2 contributions to the CMIP5 archive. J. Adv. Model. Earth Syst., 6, 141-184, doi:10.1002/2013MS000265.
Schneider, U., A. Becker, P. Finger, A. Meyer-Christoffer, M. Ziese, and B. Rudolf, 2014: GPCC's new land surface precipitation climatology based on quality-controlled in situ data and its role in quantifying the global water cycle. Theor. Appl. Climatol., 115, 15-40, doi:10.1007/s00704-013-0860-x.

Schuur, E. A. G., 2003: Productivity and global climate revisited: The sensitivity of tropical forest growth to precipitation. Ecology, 84, 1165-1170, doi:10.1890/0012-9658(2003)084[1165: PAGCRT]2.0.CO;2.

Semboli, O., D. Beina, D. Closset-Kopp, S. Gourlet-Fleury, and G. Decocq, 2014: Does long-term monitoring of tropical forests using permanent plots provide unbiased results? Appl. Veg. Sci., 17, 737-743, doi:10.1111/avsc.12097.

Shao, P., X. Zeng, K. Sakaguchi, R. K. Monson, and X. Zeng, 2013: Terrestrial carbon cycle: Climate relations in eight CMIP5 Earth system models. J. Climate, 26, 8744-8764, doi:10.1175/ JCLI-D-12-00831.1.

Silva, L. C. R., and M. Anand, 2013: Probing for the influence of atmospheric $\mathrm{CO}_{2}$ and climate change on forest ecosystems across biomes. Global Ecol. Biogeogr., 22, 83-92, doi:10.1111/ j.1466-8238.2012.00783.x.

Sombroek, W., 2001: Spatial and temporal patterns of Amazon rainfall-Consequences for the planning of agricultural occupation and the protection of primary forests. $A M B I O, \mathbf{3 0}$, 388-396, doi:10.1579/0044-7447-30.7.388.

Spiess, A.-N., and N. Neumeyer, 2010: An evaluation of $\mathrm{R}^{2}$ as an inadequate measure for nonlinear models in pharmacological and biochemical research: A Monte Carlo approach. BMC Pharmacol., 10, doi:10.1186/1471-2210-10-6.

Steiger, J. H., and L. C. Lind, 1980: Statistically based tests for the number of common factors. Proc. Annual Meeting of the Psychometric Society, Iowa City, IA, Psychometric Society, 758.

Stephenson, N. L., and Coauthors, 2011: Causes and implications of the correlation between forest productivity and tree mortality rates. Ecol. Monogr., 81, 527-555, doi:10.1890/10-1077.1.

_ global and regional patterns of productivity. Ecol. Lett., 8 , 524-531, doi:10.1111/j.1461-0248.2005.00746.x.

Taylor, K. E., R. J. Stouffer, and G. A. Meehl, 2012: An overview of CMIP5 and the experiment design. Bull. Amer. Meteor. Soc., 93, 485-498, doi:10.1175/BAMS-D-11-00094.1.

Todd-Brown, K. E. O., J. T. Randerson, W. M. Post, F. M. Hoffman, C. Tarnocai, E. A. G. Schuur, and S. D. Allison, 2013: Causes of variation in soil carbon simulations from CMIP5 Earth system models and comparison with observations. Biogeosciences, 10, 1717-1736, doi:10.5194/bg-10-1717-2013.

Trenberth, K. E., and D. J. Shea, 2005: Relationships between precipitation and surface temperature. Geophys. Res. Lett., 32 , L14703, doi:10.1029/2005GL022760.

van Vuuren, D. P., and Coauthors, 2011: The representative concentration pathways: An overview. Climatic Change, 109, 531, doi:10.1007/s10584-011-0148-z.

Watanabe, S., and Coauthors, 2011: MIROC-ESM 2010: Model description and basic results of CMIP5-20c3m experiments. Geosci. Model Dev., 4, 845-872, doi:10.5194/gmd-4-845-2011.

Wild, M., D. Folini, C. Schär, N. Loeb, E. Dutton, and G. KonigLanglo, 2013: The Earth's radiation balance and its representation in CMIP5 models. Geophysical Research Abstracts, Vol. 15, Abstract EGU2013-1286-1.

Wilks, D. S., 1999: Simultaneous stochastic simulation of daily precipitation, temperature and solar radiation at multiple sites in complex terrain. Agric. For. Meteor., 96, 85-101, doi:10.1016/ S0168-1923(99)00037-4. 
- 2006: Statistical Methods in the Atmospheric Sciences. 2nd ed. Elsevier, 627 pp.

Wright, S. J., 2013: The carbon sink in intact tropical forests. Global Change Biol., 19, 337-339, doi:10.1111/gcb.12052.

Wu, Z., P. Dijkstra, G. W. Koch, J. Peñuelas, and B. A. Hungate, 2011: Responses of terrestrial ecosystems to temperature and precipitation change: A meta-analysis of experimental manipulation. Global Change Biol., 17, 927-942, doi:10.1111/j.1365-2486.2010.02302.x.
Yin, L., R. Fu, E. Shevliakova, and R. E. Dickinson, 2013: How well can CMIP5 simulate precipitation and its controlling processes over tropical South America? Climate Dyn., 41, 3127-3143, doi:10.1007/s00382-012-1582-y.

Zhao, M., and S. W. Running, 2010: Drought-induced reduction in global terrestrial net primary production from 2000 through 2009. Science, 329, 940-943, doi:10.1126/ science.1192666. 